DIVISION OF THE HUMANITIES AND SOCIAL SCIENCES

CALIFORNIA INSTITUTE OF TECHNOLOGY

PASADENA, CALIFORNIA 91125

SECURE IMPLEMENTATION EXPERIMENTS: DO STRATEGY-PROOF MECHANISMS REALLY WORK?

Timothy N. Cason

Purdue University

Tatsuyoshi Saijo

Osaka University

California Institute of Technology

Tomas Sjöstrom

Pennsylvania State University

Takehiho Yamato

Tokyo Institute of Technology

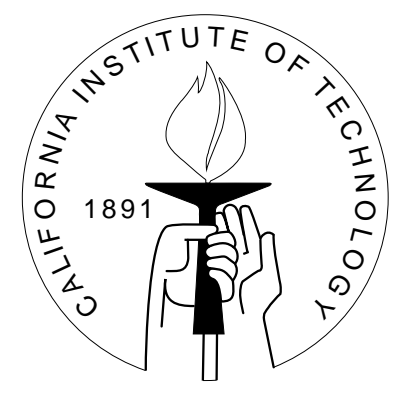

SOCIAL SCIENCE WORKING PAPER 1165

May 2003 


\title{
Secure Implementation Experiments: Do Strategy-proof Mechanisms Really Work?
}

\author{
Timothy N. Cason Tatsuyoshi Saijo Tomas Sjöstrom Takehiho Yamato
}

\begin{abstract}
Strategy-proofness, requiring that truth-telling is a dominant strategy, is a standard concept used in social choice theory. Saijo, et al., (2003) argue that this concept has serious drawbacks. In particular, announcing one's true preference may not be a unique dominant strategy, and almost all strategy-proof mechanisms have a continuum of Nash equilibria. For only a subset of strategy-proof mechanisms do the set of Nash equilibria and the set of dominant strategy equilibria coincide. For example, this double coincidence occurs in the Groves mechanism when preferences are single-peaked. We report experiments using two strategy-proof mechanisms where one of them has a large number of Nash equilibria, but the other has a unique Nash equilibrium. We found clear differences in the rate of dominant strategy play between the two.
\end{abstract}

JEL classification numbers: C92, D71, D78, H41

Key words: secure implementation, strategy-proofness, pivotal mechanism, Clarke-Groves mechanism, Nash equilibrium, Dominant equilibrium, experiment 


\section{Secure Implementation Experiments: Do Strategy-proof Mechanisms Really Work?†}

\section{Introduction}

Strategy-proofness, requiring that truth-telling is a dominant strategy, is a standard concept that has been used in the design of a variety of mechanisms for social choice as well as for eliciting values for non-market goods. Its main appeal is that it relies on what would seem to be one of the most basic game-theoretic notions and apparently innocuous assumptions for behavior: that players adopt dominant strategies. Theorists often fail to recognize, however, that laboratory evidence calls into question the descriptive relevance of this assumption. For example, Attiyeh, Franciosi, and Isaac (2000) and Kawagoe and Mori (2001) report pivotal mechanism experiments in which subjects adopt dominant strategies less than half the time, and Kagel, Harstad, and Levin (1987), Kagel and Levin (1993) and Harstad (2000) report second price auction experiments in which most bids do not reveal true value.

Experimentalists sometimes argue that players who use weakly dominated strategies must suffer from confusion due to the complexity of the mechanism and the non-transparency of the dominant strategy. But in fact, neither "epistemic" (deductive) nor "evolutive" (dynamic) models provide unambiguous support for the elimination of weakly dominated strategies. If each player is perfectly rational and can deduce what strategies the opponent will use, then the outcome of the game must be a Nash equilibrium (Aumann and Brandenburger (1995)), but there is nothing that forces a player

\footnotetext{
† Research was partially supported by the Grant in Aid for Scientific Research 08453001 of the Ministry of Education, Science and Culture in Japan, the Tokyo Center for Economic Research Grant, and the Japan Economic Research Foundation Grant.
} 
to eliminate weakly dominated strategies. In a dynamic analysis, the behavior of boundedly rational players is changing over time. While the rest points of dynamic processes such as fictitious play and replicator dynamics must be Nash equilibria, there is no guarantee that weakly dominated strategies will be eliminated. Intuitively, the feedback the players receive may be very weak because the use of a weakly dominated strategy may not cause any loss in payoff. Binmore, Gale and Samuelson (1995) and Kagel and Levin (1993) argue that this weak feedback effect can explain some experimental results, and Cabrales and Ponti (2000) discuss the implications for mechanism design. Of course, epistemic and evolutive models do provide clear-cut support for the elimination of strictly dominated strategies. The problem is that very few social choice rules are implementable in strictly dominant strategies.

Motivated by this problem, Saijo, Sjöström and Yamato (2003) developed a new concept called secure implementation. A social choice function is securely implementable if there exists a mechanism (game form) that implements it in dominant strategy equilibria, and the set of dominant strategy equilibrium outcomes and the set of Nash equilibrium outcomes coincide. That is, all Nash equilibrium outcomes must be socially optimal in a secure mechanism. The current paper takes a first step towards establishing the empirical significance of these ideas. We report a new experiment comparing the rate of dominant strategy adoption for the pivotal mechanism (where implementation is not secure) and for the Groves-Clarke mechanism when preferences are single-peaked (where implementation is secure). Our results indicate that subjects play dominant strategies significantly more often in the secure Groves-Clarke mechanism than in the non-secure 
pivotal mechanism, even though we have simplified both mechanisms with context-free payoff tables.

The practical relevance of mechanism design will increase as more mechanisms are implemented in the field. Auctions provide an important example. The English (ascending price) auction is a secure mechanism that has been used since at least 500 B.C. in Babylon (Cassady, 1967). Theorists have noted the strategic equivalence between English and second price auctions since Vickrey (1961), but for some information conditions the second price auction is strategy-proof but not securely implementable. Until recently the second price auction has not been adopted in the field, although this is likely to change as online auctions grow in importance. Bidders in online auctions at eBay and Amazon can submit a reservation price (called a proxy bid) early in the auction, and if this bid is highest then this bidder wins the auction and pays only the minimum bid increment above the secondhighest submitted price. This institution shares a number of incentive features of theoretical second price auctions, although as currently implemented submitting one's reservation price is generally not a dominant strategy (Roth and Ockenfels, 2002).

But the adoption of true sealed-bid second price auctions may grow over time, particularly for intermediate goods and in procurement (“business-to-business") transactions. ${ }^{1}$ But as we illustrate in Section 3, for some information conditions the second price auction has "bad" Nash equilibrium outcomes that are Pareto-inferior to the dominant strategy equilibrium outcome. This suggests that proponents of second price auctions may want to be more cautious when proposing them for online markets or to elicit valuations for non-market goods. 
The remainder of the paper is organized as follows. Section 2 presents a brief review of the laboratory evidence on strategy-proof mechanisms. Section 3 gives examples of two well-known strategy-proof mechanisms that have a continuum of Nash equilibria, including equilibria other than the dominant strategy equilibrium that theorists usually focus on. We characterize secure implementability in Section 4 for the case of two agents and quasi-linear preferences that is relevant for our experiment. (Saijo et al. (2003) presents results for more general conditions.) Section 5 describes the experimental environment and Section 6 contains the experimental results. Section 7 provides concluding remarks.

\section{Experimental Results on Strategy-Proof Mechanisms}

Until recently, most of the experimental studies of strategy-proof mechanisms have considered the second price auction (Vickrey, 1961). For example, Coppinger, Smith and Titus (1980) studied the relationship between Dutch, English, first price sealed-bid and second price sealed-bid auctions. Bidders in both the English and the second price auction have a dominant strategy to fully reveal their resale value in their bid (or reveal their value in their "drop-out price" in the case of the English auction). Bidders in Coppinger et al.'s (oral) English auctions typically dropped out of the bidding when predicted, so prices corresponded to the equilibrium prediction - the second-highest bidders' resale value. Similarly, Kagel, Harstad and Levin (1987) show that bidders in English (clock) auctions lock on to the dominant strategy of bidding equal to value after a few periods of initially overbidding.

\footnotetext{
${ }^{1}$ Some examples where sealed-bid second price auctions have been introduced for business-to-consumer and consumer-to-consumer transactions include qconlineauction.com and grab-a-deal.com.
} 
Bidders in Coppinger et al.'s second price auctions did not bid above their resale value, but this is clearly because of the artificial prohibition of bids above resale value imposed in these initial experiments. Kagel and Levin (1993) find that 58 to 67 percent of second price auction bids are greater than resale value, which they attribute to (1) the equilibrium bidding strategy being less transparent than in the English auction and (2) learning feedback to discourage overbidding is weak under sealed-bid procedures because typically the overbidding is not "punished" with losses. Harstad (2000) also documents rather severe overbidding in second price auctions that does not decline over time but that may be less pronounced when subjects first obtain experience in English auctions. Garratt, Walker and Wooders (2002) show that bidders who are highly experienced in online auctions are no more likely to overbid than to underbid, but as with inexperienced bidders only very few (roughly 20 percent) of bids are approximately equal to value. Most bids in the Garratt et al. study vary considerably from the bidders' true values, and consequently less than one half of the auctions result in efficient allocations. Overall the data clearly indicate that subjects do not play their dominant strategy, and in all cases the evidence suggests that bidding equal to value is significantly more common in English than in second price auctions.

While the transparency, experience and feedback explanations for the lower frequency of dominant strategy play in the second price auction are all plausible, we propose a complementary explanation that may be relevant for auctions conducted in the field. For the incomplete information conditions implemented in most laboratory experiments the only Nash equilibrium coincides with the dominant strategy equilibrium in which bids fully reveal values. But in more realistic information conditions in which 
bidders have some information about their rivals' values - through repeated interaction for example -Nash equilibria that do not coincide with the dominant strategy equilibrium exist and involve overbidding and underbidding. For example, suppose bidder 1 has a value of $\$ 555$ and bidder 2 has a value of $\$ 550$, and that these values are common knowledge. It is a Nash equilibrium for bidder 1 to bid $\$ 540$ and bidder 2 to bid $\$ 560$, resulting in the inefficient allocation of the object to bidder 2. Kagel and Levin (1993) and others have noted that overbidding is not discouraged because bidders can bid above values and not lose money. It is precisely this feature of the second price auction institution that causes "bad" Nash equilibria to exist. Saijo et al. (2003) discuss many other examples of strategy-proof mechanisms that also have bad Nash equilibrium outcomes that are Pareto-inferior to the dominant strategy equilibrium outcome.

More recent experiments have studied the pivotal mechanism, which is a strategyproof social choice mechanism that is strategically equivalent to the second price auction..$^{2,3}$ In this mechanism an agent pays the amount needed to implement his preferred outcome only if his report is pivotal and changes the chosen outcome. These studies have also documented that subjects frequently do not play dominant strategies. Attiyeh, Franciosi and Isaac (2000) find that less than 10 percent of the bids reveal the subjects' true value for the public good, in a setting where the experimenter explained the mapping of bids to outcomes (and required taxes for the pivotal players) for five- and ten-person

\footnotetext{
2 Another truth-telling mechanism that has been widely employed in experiments is the Becker-DeGrootMarshak (BDM) mechanism. In this mechanism the subject states a maximum buying price or minimum selling price, but the actual buying or selling price is determined by a randomizing device and the transaction is carried out if it is acceptable giving the subject's reported maximum or minimum. This mechanism is not a game so it is not directly relevant for our study.

${ }^{3}$ We do not review here other social choice mechanism experiments like the serial cost sharing mechanism because the researchers have implemented those mechanisms in environments where the Nash equilibria are not in dominant strategies (e.g., Chen, 2003; Dorsey and Razzolini, 1999).
} 
groups. Part of the poor performance of this mechanism might be due to subject confusion and the complexity of the pivotal mechanism. Kawagoe and Mori (2001) provide support for this interpretation, using a controlled experiment that manipulates the complexity across treatments. They also find that only a small number of bids (less than 20 percent) reveal true values when the context and complexity of the pivotal mechanism is part of the experiment; but when the mechanism is simplified and represented by (detailed) payoff tables then nearly half of the subjects play the dominant strategy. In the present experiment we also study the pivotal mechanism with detailed payoff tables to help simplify the decision environment and promote equilibrium bids. Although confusion and complexity may be partly responsible for the poor performance of some mechanisms, we will try to go beyond this explanation. We will argue that the existence of multiple Nash equilibria allows us to predict how behavior will deviate from the dominant strategy equilibrium. That is, we will identify systematic rather than random deviations from the dominant strategy equilibrium in non-secure mechanisms.

\section{Why do Strategy-Proof Mechanisms Not Work Well?}

Saijo et al. (2003) show that many of the strategy-proof mechanisms that have been studied in the literature have a continuum of Nash equilibrium outcomes that do not coincide with the dominant strategy equilibrium outcome. In particular, they present a number of examples including the pivotal mechanism for a non-excludable public good, the serial cost sharing mechanism for an excludable public good, the second price auction for an indivisible good, the Condorcet winner voting scheme (a median voter scheme) with single-peaked preferences, and the uniform allocation rule (a fixed-price trading rule) with single-peaked preferences. Besides having a continuum of Nash equilibria, these 
mechanisms all have bad Nash equilibrium outcomes that are Pareto-inferior to the dominant strategy equilibrium outcome. Here we provide more details for the two examples of such strategy-proof mechanisms that were just summarized from the experimental literature.

Example 1: The pivotal mechanism (Clarke, 1971).

Consider the pivotal mechanism, which is one of the two mechanisms studied in the present experiment, for a two-agent economy with a binary non-excludable public good and quasi-linear preferences. Two agents 1 and 2 are facing a decision whether or not they should produce the public good. Agent $i$ 's true net value of the public good is $v_{i}$ if it is produced, and her true net value is 0 otherwise $(i=1,2)$. In the pivotal mechanism, each agent $i$ reports his net value $\widetilde{v}_{i}$ and the outcome is determined as follows:

Rule 1: if $\widetilde{v}_{1}+\widetilde{v}_{2} \geq 0$, then the public good is produced, and if not, then it is not produced; and

Rule 2: each agent $i$ must pay the pivotal tax $t_{i}$

$t_{i}=\left\{\begin{array}{cl}0 & \text { if (i) } \widetilde{v}_{j}\left(\widetilde{v}_{1}+\widetilde{v}_{2}\right)>0 \text { or (ii) } \widetilde{v}_{j}>0 \text { and } \widetilde{v}_{1}+\widetilde{v}_{2}=0 \\ \left|\widetilde{v}_{j}\right| & \text { otherwise }\end{array}\right.$

where $j \neq i$.

That is, an agent pays the amount needed to implement his preferred outcome if his report is pivotal and changes the chosen outcome.

First, let $\left(v_{1}, v_{2}\right)=(5,-4)$ be the true net value vector. Figure 1-(a) shows that the set of Nash equilibria is approximately a half of the two dimensional area. Notice that the public good should be produced because the sum of the net values of the public good is positive. The upper-right part of the set of Nash equilibria is good since constructing the 
public good is recommended. However, the lower-left part of the set of Nash equilibria is bad since producing the public good is not recommended.

Second, let $\left(v_{1}, v_{2}\right)=(5,5)$ be the true net value vector. In this case, both agents want to construct the public good. However, Figure 1-(b) shows the area of bad Nash equilibria is still large. Saijo et al. (2003) generalize this negative result to the case with any arbitrary finite numbers of public projects and agents.

Figure 1 is around here.

Example 2: The second price auction (Vickrey (1961)).

Consider a two-agent model with an indivisible good. Agent $i$ 's true value of the good is $v_{i} \geq 0$ if she receives it, and her true value is 0 otherwise $(i=1,2)$. Let $\left(\widetilde{v}_{1}, \widetilde{v}_{2}\right)$ be a reported value vector. The second price auction consists of two rules:

Rule 1: if $\widetilde{v}_{i}>\widetilde{v}_{j}$, then agent $i$ receives the good and pays $\widetilde{v}_{j}(i, j=1,2 ; i \neq j)$; and Rule 2: if $\widetilde{v}_{1}=\widetilde{v}_{2}$, then agent 1 receives the good and pays $\widetilde{v}_{2}$.

Let $\left(v_{1}, v_{2}\right)=(7,5)$ be the true value vector. Figure 2 shows that the set of Nash equilibria is quite large. Notice that agent 1 should receive the good because her value is greater than agent 2's. The lower-right part of the set of Nash equilibria is good since agent 1 receives the good. However, the upper-left part of the set of Nash equilibria involving overbidding is bad since agent 2 receives the good.

Figure 2 is around here. 
We do not dispute the possibility that, in practice, some confused bidders may fail to recognize their dominant strategy because it is not transparent (e.g., Harstad, 2000). However, our key observation is that the Nash equilibrium areas shown in Figure 2 indicate the possibility of systematic rather than random deviations from the dominant strategy equilibrium.

\section{Secure Implementation in Public Good Economies}

The previous section presented two examples drawn from many strategy-proof mechanisms that may have "bad" Nash equilibria. They implement the social choice function (SCF) in dominant strategies, but not in Nash equilibria. Saijo et al. (2003) introduce a new concept of implementation, called secure implementation, which does not share this shortcoming.

We introduce notation and definitions here to describe the concept of secure implementation in the context of public good economies with two agents and quasi-linear preferences. Denote the set of feasible allocations by

$$
A=\left\{\left(y, t_{1}, t_{2}\right) \mid y \in Y, t_{1}, t_{2} \in \mathfrak{R}\right\},
$$

where $Y \subseteq \Re$ is a production possibility set, $y \in Y$ is an output level of a public good, and $t_{i}$ is a transfer of a private good to agent $i$. For simplicity, we assume that there is no cost involved in producing $y$. Each agent $i$ 's utility function, $u_{i}: A \rightarrow \Re$, is selfish and quasilinear:

$$
u_{i}\left(y, t_{1}, t_{2}\right)=u_{i}\left(y, t_{i}\right)=v_{i}(y)+t_{i}, \quad i=1,2 .
$$

The class of valuation functions, $v_{i}: Y \rightarrow \Re$, admissible for agent $i$ is denoted by $V_{i}$. Let $v$ $=\left(v_{1}, v_{2}\right) \in V \equiv V_{1} \times V_{2}$ be a valuation profile. 
A social choice function (SCF) is a function $f: V \rightarrow A$ that associates with every list of valuation functions, $v \in V$, a unique feasible allocation $f(v)$ in $A$. The allocation $f(v)$ is said to be f-optimal for $v$.

A mechanism (or game form) is a function $g: S_{1} \times S_{2} \rightarrow A$ that assigns to every $\left(s_{1}, s_{2}\right) \in S_{1} \times S_{2}$ a unique element of $A$, where $S_{i}$ is the strategy space of agent $i$. For a strategy profile $s=\left(s_{1}, s_{2}\right) \in S_{1} \times S_{2}$, the outcome of $g$ for the profile $s$ is denoted by $g(s)=\left(y^{g}(s), t^{g}(s)\right)$, where $y^{g}(s)$ is the level of the public good and $t^{g}(s)=\left(t_{1}^{g}(s), t_{2}^{g}(s)\right)$ is the transfer vector.

The strategy profile $s=\left(s_{1}, s_{2}\right) \in S_{1} \times S_{2}$ is a Nash equilibrium of $g$ at $v \in V$ if

$$
\begin{aligned}
& v_{1}\left(y^{g}\left(s_{1}, s_{2}\right)\right)+t_{1}^{g}\left(s_{1}, s_{2}\right) \geq v_{1}\left(y^{g}\left(s_{1}^{\prime}, s_{2}\right)\right)+t_{1}^{g}\left(s_{1}^{\prime}, s_{2}\right) \text { for all } s_{1}^{\prime} \in S_{1}, \text { and } \\
& v_{2}\left(y^{g}\left(s_{1}, s_{2}\right)\right)+t_{2}^{g}\left(s_{1}, s_{2}\right) \geq v_{2}\left(y^{g}\left(s_{1}, s_{2}^{\prime}\right)\right)+t_{2}^{g}\left(s_{1}, s_{2}^{\prime}\right) \text { for all } s_{2}^{\prime} \in S_{2} .
\end{aligned}
$$

Let $N_{A}^{g}(v)$ be the set of Nash equilibrium allocations of $g$ at $v$, i.e., $N_{A}^{g}(v) \equiv\left\{\left(\left(y, t_{1}, t_{2}\right) \in A\right.\right.$ | there exists a Nash equilibrium at $v, s \in S$, such that $\left.g(s)=\left(y, t_{1}, t_{2}\right)\right\}$.

The strategy profile $s=\left(s_{1}, s_{2}\right) \in S_{1} \times S_{2}$ is a dominant strategy equilibrium of $g$ at $v \in$ $V$ if

$$
\begin{aligned}
& v_{1}\left(y^{g}\left(s_{1}, s_{2}^{\prime}\right)\right)+t_{1}^{g}\left(s_{1}, s_{2}^{\prime}\right) \geq v_{1}\left(y^{g}\left(s_{1}^{\prime}, s_{2}^{\prime}\right)\right)+t_{1}^{g}\left(s_{1}^{\prime}, s_{2}^{\prime}\right) \text { for all } s_{1}^{\prime} \in S_{1} \text { and } s_{2}^{\prime} \in S_{2} ; \text { and } \\
& v_{2}\left(y^{g}\left(s_{1}^{\prime}, s_{2}\right)\right)+t_{2}^{g}\left(s_{1}^{\prime}, s_{2}\right) \geq v_{2}\left(y^{g}\left(s_{1}^{\prime}, s_{2}^{\prime}\right)\right)+t_{2}^{g}\left(s_{1}^{\prime}, s_{2}^{\prime}\right) \text { for all } s_{1}^{\prime} \in S_{1} \text { and } s_{2}^{\prime} \in S_{2} .
\end{aligned}
$$

Let $D_{A}^{g}(v)$ be the set of dominant strategy equilibrium allocations of $g$ at $v$, i.e., $D_{A}^{g}(v) \equiv$ $\left\{\left(\left(y, t_{1}, t_{2}\right) \in A \mid\right.\right.$ there exists a dominant strategy equilibrium at $v, s \in S$, such that $\left.g(s)=\left(y, t_{1}, t_{2}\right)\right\}$.

Definition 1. The mechanism $g$ implements the SCF $f$ in dominant strategy equilibria if for all $v$ $\in V, f(v)=D_{A}^{g}(v) . f$ is implementable in dominant strategy equilibria if there exists a mechanism which implements $f$ in dominant strategy equilibria. 
Definition 2. The mechanism $g$ securely implements the SCF $f$ if for all $v \in V, f(v)=D_{A}^{g}(v)=$ $N_{A}^{g}(v) .{ }^{4}$ The SCF $f$ is securely implementable if there exists a mechanism which securely implements $f$.

Dominant strategy implementation requires that for every possible preference profile, the dominant strategy equilibrium outcome coincides with the $f$-optimal outcome. In addition to this requirement, secure implementation demands that there be no Nash equilibrium outcome other than the dominant strategy equilibrium outcome.

Saijo et al. (2003) characterize the class of securely implementable SCF's using two conditions. The first condition is strategy-proofness. The allocation recommended by the SCF $f$ for the profile $v=\left(v_{1}, v_{2}\right)$ is denoted by $f(v)=\left(y^{f}(v), t^{f}(v)\right)$, where $y^{f}(v)$ is the level of the public good and $t^{f}(v)=\left(t_{1}^{f}(v), t_{2}^{f}(v)\right)$ is the transfer vector.

Definition 3. The SCF $f$ is strategy-proof if

$$
\begin{aligned}
& v_{1}\left(y^{f}\left(v_{1}, \widetilde{v}_{2}\right)\right)+t_{1}^{f}\left(v_{1}, \widetilde{v}_{2}\right) \geq v_{1}\left(y^{f}\left(\widetilde{v}_{1}, \widetilde{v}_{2}\right)\right)+t_{1}^{f}\left(\widetilde{v}_{1}, \widetilde{v}_{2}\right) \text { for all } \tilde{v}_{1} \in V_{1} \text { and } \tilde{v}_{2} \in V_{2} ; \text { and } \\
& v_{2}\left(y^{f}\left(\tilde{v}_{1}, v_{2}\right)\right)+t_{2}^{f}\left(\tilde{v}_{1}, v_{2}\right) \geq v_{2}\left(y^{f}\left(\tilde{v}_{1}, \tilde{v}_{2}\right)\right)+t_{2}^{f}\left(\tilde{v}_{1}, \tilde{v}_{2}\right) \text { for all } \widetilde{v}_{1} \in V_{1} \text { and } \widetilde{v}_{2} \in V_{2} .
\end{aligned}
$$

By the Revelation Principle (Gibbard, 1973), strategy-proofness is necessary for dominant strategy implementation, and therefore also for secure implementation. However, an additional condition is necessary for secure implementation. To see why intuitively, suppose that the direct revelation mechanism $g=f$ securely implements the $\operatorname{SCF} f$. See Figure 3 in which $n=2$ and $\left(v_{1}, v_{2}\right)$ is the true preference profile. Suppose $u_{1}\left(f\left(v_{1}, \widetilde{v}_{2}\right)\right)=u_{1}\left(f\left(\widetilde{v}_{1}, \widetilde{v}_{2}\right)\right)$, i.e.,

\footnotetext{
4 Secure implementation is identical to double implementation in dominant strategy equilibria and Nash equilibria. It was Maskin (1979) who first introduced the concept of double implementation. See also Yamato (1993).
} 


$$
v_{1}\left(y^{f}\left(v_{1}, \widetilde{v}_{2}\right)\right)+t_{1}^{f}\left(v_{1}, \widetilde{v}_{2}\right)=v_{1}\left(y^{f}\left(\widetilde{v}_{1}, \widetilde{v}_{2}\right)\right)+t_{1}^{f}\left(\widetilde{v}_{1}, \widetilde{v}_{2}\right) .
$$

In other words, agent 1 is indifferent between reporting the true preference $v_{1}$ and reporting another preference $\widetilde{v}_{1}$ when agent 2 's report is $\widetilde{v}_{2}$. Since reporting $v_{1}$ is a dominant strategy by strategy-proofness, it follows from (4.1) that

$$
\begin{aligned}
v_{1}\left(y^{f}\left(\widetilde{v}_{1}, \widetilde{v}_{2}\right)\right)+t_{1}^{f}\left(\widetilde{v}_{1}, \widetilde{v}_{2}\right) & =v_{1}\left(y^{f}\left(v_{1}, \widetilde{v}_{2}\right)\right)+t_{1}^{f}\left(v_{1}, \widetilde{v}_{2}\right) \\
& \geq v_{1}\left(y^{f}\left(v_{1}^{\prime}, \widetilde{v}_{2}\right)\right)+t_{1}^{f}\left(v_{1}^{\prime}, \widetilde{v}_{2}\right)
\end{aligned}
$$

for all $v_{1}^{\prime} \in V_{1}$, that is, reporting $\widetilde{v}_{1}$ is one of agent 1 's best responses when agent 2 reports $\widetilde{v}_{2}$

Next suppose that $u_{2}\left(f\left(\widetilde{v}_{1}, v_{2}\right)\right)=u_{2}\left(f\left(\widetilde{v}_{1}, \widetilde{v}_{2}\right)\right)$, i.e.,

By using an argument similar to the above, it is easy to see that

$$
\begin{aligned}
v_{2}\left(y^{f}\left(\widetilde{v}_{1}, \widetilde{v}_{2}\right)\right)+t_{2}^{f}\left(\widetilde{v}_{1}, \widetilde{v}_{2}\right) & =v_{2}\left(y^{f}\left(\widetilde{v}_{1}, v_{2}\right)\right)+t_{2}^{f}\left(\widetilde{v}_{1}, v_{2}\right) \\
& \geq v_{2}\left(y^{f}\left(\widetilde{v}_{1}, v_{2}^{\prime}\right)\right)+t_{1}^{f}\left(\widetilde{v}_{1}, v_{2}^{\prime}\right)
\end{aligned}
$$

for all $v_{2}^{\prime} \in V_{2}$, that is, reporting $\widetilde{v}_{2}$ is one of agent 2's best responses when agent 1 reports $\widetilde{v}_{1}$. Therefore, $f\left(\widetilde{v}_{1}, \widetilde{v}_{2}\right)=\left(y^{f}\left(\widetilde{v}_{1}, \widetilde{v}_{2}\right), t^{f}\left(\widetilde{v}_{1}, \widetilde{v}_{2}\right)\right)$ is the Nash equilibrium outcome.

Moreover, $f\left(v_{1}, v_{2}\right)=\left(y^{f}\left(v_{1}, v_{2}\right), t^{f}\left(v_{1}, v_{2}\right)\right)$ is the dominant strategy outcome, and by secure implementability, the dominant strategy outcome coincides with the Nash equilibrium outcome. Accordingly we conclude that $f\left(v_{1}, v_{2}\right)=f\left(\widetilde{v}_{1}, \widetilde{v}_{2}\right)$ if $(4.1)$ and (4.2) holds.

Figure 3 is around here.

A formal definition of this condition, called the rectangular property, is given as follows: 
Definition 4. The SCF $f$ satisfies the rectangular property if for all $v, \widetilde{v} \in V$, if $v_{1}\left(y^{f}\left(v_{1}, \widetilde{v}_{2}\right)\right)+t_{1}^{f}\left(v_{1}, \widetilde{v}_{2}\right)=v_{1}\left(y^{f}\left(\widetilde{v}_{1}, \widetilde{v}_{2}\right)\right)+t_{1}^{f}\left(\widetilde{v}_{1}, \widetilde{v}_{2}\right)$ and $v_{2}\left(y^{f}\left(\widetilde{v}_{1}, v_{2}\right)\right)+t_{1}^{f}\left(\widetilde{v}_{1}, v_{2}\right)=v_{2}\left(y^{f}\left(\widetilde{v}_{1}, \widetilde{v}_{2}\right)\right)+t_{2}^{f}\left(\widetilde{v}_{1}, \widetilde{v}_{2}\right)$, then $f\left(v_{1}, v_{2}\right)=f\left(\widetilde{v}_{1}, \widetilde{v}_{2}\right)$.

Saijo et al. (2003) show that the rectangular property is necessary and sufficient for sure implementation:

Theorem 1. An SCF is securely implementable if and only if it satisfies strategy-proofness and the rectangular property.

By applying Theorem 1, Saijo et al. (2003) find that none of the strategy-proof and efficient SCF's is securely implementable if public goods are discrete. But strategy-proof and efficient SCF's are securely implementable by Groves-Clarke mechanisms with singlepeaked preferences.

Consider an SCF $f$ satisfying the efficiency condition on the public good provision:

$$
y^{f}\left(v_{1}, v_{2}\right) \in \arg \max _{y \in Y}\left[v_{1}(y)+v_{2}(y)\right] \text { for all }\left(v_{1}, v_{2}\right) \in V
$$

The following result is well known:

Proposition 1 (Clarke (1971), Groves (1973), Green and Laffont (1979)). An SCF $f$ satisfying (4.3) is implementable in dominant strategy equilibria if and only if $f$ satisfies

(4.4) $t_{1}^{f}\left(v_{1}, v_{2}\right)=v_{2}\left(y^{f}\left(v_{1}, v_{2}\right)\right)+h_{1}\left(v_{2}\right), t_{2}^{f}\left(v_{1}, v_{2}\right)=v_{1}\left(y^{f}\left(v_{1}, v_{2}\right)\right)+h_{2}\left(v_{1}\right) \forall\left(v_{1}, v_{2}\right) \in V$, where $h_{i}$ is some arbitrary function which does not depend on $v_{i}$. 
A direct revelation mechanism satisfying (4.3) and (4.4) is called a Groves-Clarke mechanism. Proposition 1 says that we can focus on the class of Groves-Clarke mechanisms for implementation of an efficient SCF in dominant strategy equilibria. However, Saijo et al. (2003) show that for any mechanism implementing an efficient SCF in dominant strategy equilibria, the set of Nash equilibrium outcomes is strictly larger than that of dominant strategy equilibrium outcomes if the number of public project choices is finite.

Results are different for single-peaked preferences. In this case strategy-proof and efficient SCF's are securely implementable by Groves-Clarke mechanisms. Suppose that $Y=\Re$ and for $i=1,2$,

$$
V_{i}=\left\{v_{i}: \mathfrak{R} \rightarrow \mathfrak{R} \mid v_{i}(y)=-\left(y-r_{i}\right)^{2}, r_{i} \in \mathfrak{R}\right\},
$$

where $r_{i}$ is agent $i$ 's most preferred level of the public good. We can represent these single-peaked preferences by the $r_{i}$ instead of the $v_{i}$. The optimal output level of the public good satisfying (4.3) is given by $y\left(r_{1}, r_{2}\right)=\left(r_{1}+r_{2}\right) / 2$.

For this case any SCF $f$ meeting (4.3) and (4.4) satisfies the rectangular property and is therefore securely implementable (Saijo et al., 2003).

Consider an example that will be used in our experimental design later, in which $h_{i}=0$. Then,

$$
\begin{aligned}
u_{1}\left(\widetilde{r}_{1}, \widetilde{r}_{2}\right) & =v_{1}\left(y\left(\widetilde{r}_{1}, \widetilde{r}_{2}\right)\right)+t_{1}\left(\widetilde{r}_{1}, \widetilde{r}_{2}\right)=-\left(\left(\widetilde{r}_{1}+\widetilde{r}_{2}\right) / 2-r_{1}\right)^{2}-\left(\left(\widetilde{r}_{1}+\widetilde{r}_{2}\right) / 2-\widetilde{r}_{2}\right)^{2} \\
& =-\left\{\left(\widetilde{r}_{1}-r_{1}\right)^{2}+\left(\widetilde{r}_{2}-r_{1}\right)^{2}\right\} / 2
\end{aligned}
$$

where $r_{1}$ is player 1 's true peak and $\left(\widetilde{r}_{1}, \widetilde{r}_{2}\right)$ is a vector of reported peaks. Clearly agent 1 's payoff is maximized at $r_{1}$. Since the payoff function is quadratic, no other maximizers exist. Furthermore, the payoff is maximized at $r_{1}$ regardless $\widetilde{r}_{2}$. Figure 4 shows agent 1 's payoff when $r_{1}=12$. If $\widetilde{r}_{2}=4$, the maximizer is $a$, and if $\widetilde{r}_{2}=12$, it is $b$. Both are 
maximized at $r_{1}=12$. Therefore, the best response curve is a line parallel to the $\widetilde{r}_{2}$ axis. This indicates that truth-telling is the dominant strategy. In fact, it is strictly dominant. However, this is true only as long as the public goods level is continuously variable. In our experiment, we will discretize the public goods level and the payoff functions, and truthtelling will not be strictly dominant even though preferences are single-peaked. ${ }^{5}$ However, with single-peaked preferences all Nash equilibria will be "good," so implementation will be secure.

Figure 4 is around here.

\section{The Experiment}

Our experiment studies the pivotal mechanism and a Groves-Clarke mechanism with single-peaked preferences. It consisted of four sessions with 20 subjects each $(80$ total subjects). We conducted two sessions in Treatment $\mathrm{P}$ that corresponded to the pivotal mechanism and two sessions in Treatment $S$ that corresponded to a Groves mechanism with single-peaked preferences.

\subsection{Design}

We conducted two sessions (one P and one S) at Tokyo Metropolitan University during June of 1998 and two sessions (one P and one S) at Purdue University during February of 2003. Each session took approximately one hour to complete.

Treatment $\mathrm{P}$ implements the pivotal mechanism for a two-person group. The net true value vector $\left(v_{1}, v_{2}\right)$ is equal to $(-6,8)$ if a binary public good is produced and $\left(v_{1}, v_{2}\right)=(0,0)$ otherwise. The public good should be produced since $v_{1}+v_{2} \geq 0$. Let the

\footnotetext{
${ }^{5}$ In general, with a discrete public good, single-peaked preferences will not assure the existence of a strictly dominant strategy. However, secure implementation will be assured.
} 
strategy space of type 1 be the set of integers from -22 to 2 , and the strategy space of type 2 be the set of integers from -4 to 20 . According to the rules of the pivotal mechanism described in Section 3, we can construct the payoff matrix of types 1 and 2 as Tables C-1 and C-2 shown in Appendix C.

The payoff tables that we actually distributed to subjects in Treatment $\mathrm{P}$ were Tables 1 and 2 whose basic structures were the same as Tables C-1 and C-2. But we modified Tables C-1 and C-2 as follows. First, we changed the names of strategies. Type 1 's strategy "-22" was renamed "1", "-21" was renamed "2", and so on. Similarly, type 2's strategy "-4" was renamed "1", "-3" was renamed "2", and so on. Second, we employed a linear transformation of the valuation functions: $14 v_{1}+294$ for type 1 and $14 v_{2}+182$ for type 2. Of course, the equilibrium regions shown on these versions of the tables were not displayed to subjects.

Tables 1 and 2 are around here.

Treatment $\mathrm{S}$ is the same as Treatment $\mathrm{P}$ except for the payoff tables. The payoff tables for Treatment $S$ are based on the following model of a Groves mechanism with single-peaked preferences with two players. Suppose that the true valuation functions of agent types 1 and 2 are respectively $v_{1}(y)=-(y-12)^{2}$ and $v_{2}(y)=-(y-17)^{2}$, where $y \in \mathfrak{R}_{+}$is the level of a public good. Each type reports his most preferred level of the public good called a peak. Given a vector of reported peaks $\left(\widetilde{r}_{1}, \widetilde{r}_{2}\right)$, the level of the public good, $y\left(\widetilde{r}_{1}, \widetilde{r}_{2}\right)$, and the transfer to type $i, t_{i}\left(\widetilde{r}_{1}, \widetilde{r}_{2}\right)$, are determined by a Groves mechanism: $y\left(\widetilde{r}_{1}, \widetilde{r}_{2}\right)=\left(\widetilde{r}_{1}+\widetilde{r}_{2}\right) / 2$ and $t_{i}\left(\widetilde{r}_{1}, \widetilde{r}_{2}\right)=-\left(\left(\widetilde{r}_{1}+\widetilde{r}_{2}\right) / 2-\widetilde{r}_{j}\right)^{2}, i, j=1,2 ; j \neq i$. The payoff functions are therefore given by

$$
\begin{aligned}
& v_{1}\left(y\left(\widetilde{r}_{1}, \widetilde{r}_{2}\right)\right)+t_{1}\left(\widetilde{r}_{1}, \widetilde{r}_{2}\right)=-\left(\left(\widetilde{r}_{1}+\widetilde{r}_{2}\right) / 2-12\right)^{2}-\left(\left(\widetilde{r}_{1}+\widetilde{r}_{2}\right) / 2-\widetilde{r}_{2}\right)^{2}, \\
& v_{2}\left(y\left(\widetilde{r}_{1}, \widetilde{r}_{2}\right)\right)+t_{2}\left(\widetilde{r}_{1}, \widetilde{r}_{2}\right)=-\left(\left(\widetilde{r}_{1}+\widetilde{r}_{2}\right) / 2-17\right)^{2}-\left(\left(\widetilde{r}_{1}+\widetilde{r}_{2}\right) / 2-\widetilde{r}_{1}\right)^{2} .
\end{aligned}
$$


Let the strategy space of each type be the set of integers from 0 to 24 . The payoff table for types 1 and 2 are is given by Tables C-3 and C-4 in Appendix C.

The payoff tables used in Treatment $S$ were Tables 3 and 4 whose basic structures were the same as Tables C-3 and C-4, modified as follows. First, we changed the names of strategies: strategy "0" was renamed "1", "1" was renamed "2", and so on. Second, we employed a linear transformation of the payoff functions: $10 v_{i} / 14+218.5$ for $i=1,2$.

Tables 3 and 4 are around here.

Note that because we discretized the possible levels in the payoff tables and rounded payoffs to the nearest whole number, neither player type has a strictly dominant strategy. Therefore, Treatments $\mathrm{S}$ and $\mathrm{P}$ cannot be differentiated in terms of strictly dominant strategies. However, only Treatment $S$ involves a secure mechanism.

\subsection{Procedures}

The sessions in Japan and in the United States involved a variety of procedural differences. They were not intended to replicate the same experimental conditions, but instead were useful to evaluate the robustness of our findings to different subject pools and procedures. Most notably, the sessions in Japan were run "by hand" with pen and paper, and the sessions in the U.S. were computerized using zTree (Fischbacher, 1999). If we had observed significant differences across experiment sites, then we would not be able to identify the source of those differences without further experimentation. Fortunately, as we show in the Appendix B the data do not indicate any meaningful statistically significant differences across sites within either mechanism treatment.

In the Japan sessions the twenty subjects were seated at desks in a relatively large room and had identification numbers assigned randomly. These ID numbers were not 
publicly displayed, however, so subjects could not determine who had which number. In the U.S. sessions the twenty subjects were seated at computer stations in the Vernon Smith Experimental Economics Laboratory that were separated with visual partitions. In every period, each of the type 1 subjects was paired with one of the type 2 subjects. The pairings were determined in advance by experimenters so as not to pair the same two subjects more than once ("strangers"). Each subject received written instructions, a record sheet, a payoff table, and (in the Japan sessions only) information transmission sheets. Instructions (see Appendix A) were also given by tape recorder in Japan and were read aloud by the experimenter in the U.S. Each subject chose her number from an integer between 1 and 25 by looking at her own payoff table only. ${ }^{6}$ No subject knew the payoff table of the other type. Moreover, we provided no explanation regarding the rules of the mechanisms or how the payoff tables were constructed.

After deciding which number she chose, each subject marked the number on an information transmission sheet (Japan) or typed in her number on her computer (U.S.). Experimenters collected these information transmission sheets and then redistributed them to the paired subjects in Japan. The computer network handled the message transmission in the U.S. Each period, subjects in both countries were asked to fill out the reasons why they chose these numbers. After learning the paired subject's choice, subjects calculated their payoffs from the payoff tables (Japan) or verified the computer-calculated payoffs (U.S.). Record sheets were identical (except for the language translation, of course) at the two sites. These steps were repeated for eight periods in Japan and for ten periods in the U.S. Recall that subjects were never paired together for more than one period.

\footnotetext{
${ }^{6}$ We required subjects to examine their payoff table for ten minutes before we began the real periods.
} 
In the Japan sessions the mean payoff per subject was 1677 yen in Treatment $S$ and it was 1669 yen in Treatment P. In the U.S. sessions the mean payoff per subject was $\$ 21.04$ in Treatment $\mathrm{S}$ and it was $\$ 20.35$ in Treatment $\mathrm{P}$.

\section{Results}

\subsection{Treatment $P$}

Tables 1 and 2 specify the dominant strategy equilibria and the other Nash equilibria for Treatment $P$. Type 1 's dominant strategies are 16 and 17 , and type 2 's dominant strategies are 12 and 13 . Notice that the dominant strategy equilibria $(16,12)$ and $(16,13)$ are Pareto-dominated by the dominant strategy equilibria $(17,12)$ and $(17,13)$. In Table 1, the lower-right region of Nash equilibria is good since the public good is produced. The upper-left region of Nash equilibria is bad since the public good is not produced. The number of good Nash equilibria is 162, while the number of bad Nash equilibria is 165 . Implementation is clearly not secure.

Since each period had 20 pairs of players and each session had 8 or 10 periods, we have 180 pairs of data. Denote each pair by $\left(x_{1}, x_{2}\right)$ where $x_{i}$ is a number chosen by a subject of type $i, i=1,2$. Figure 5 shows the frequency distribution of all data in Treatment P. The maximum frequency pair was $(16,12)$ with 34 pairs, the second was $(16,13)$ with 27 pairs, the third was $(17,13)$ with 19 pairs, and the fourth was $(17,12)$ with 10 pairs. The total frequency of the four dominant strategy equilibria $(16,12),(16,13),(17,12)$, and $(17,13)$ was 90-exactly one-half of the outcomes. The frequency of Pareto-dominated dominant strategy equilibria $(16,12)$ and $(16,13)$ was 61 , while the frequency of the dominant strategy equilibria $(17,12)$ and $(17,13)$ was 29.7 Fifty-nine other outcomes were good Nash

\footnotetext{
7 We are puzzled by the greater frequency of Pareto dominated dominant strategy equilibria. Seventy-two percent of the dominant strategies played by Type 1 players were 16 rather than 17 . The greater frequency of 16 declines in later periods, however, and only in periods 1 and 3 is 16 significantly more frequent than 17 at the 5-percent level (two-tailed) according to a binomial test.
} 
equilibria other than dominant strategy equilibria. Only one pair in one period played a bad Nash equilibrium. Although nearly half $(298 / 621)$ of the strategy pairs shown in Tables 1 and 2 that are not dominant strategy equilibrium outcomes are not Nash equilibria, only one-third (30/90) of the observed non-dominant-strategy outcomes were not Nash equilibria. This suggests that deviations from the dominant strategy equilibria are not random, but are instead more likely to correspond to Nash equilibria.

Figure 5 is around here

We conducted period by period tests of the hypothesis that the mean choice is equal to a dominant strategy (16 or 17 for type 1 and 12 or 13 for type 2 ). A nonparametric Wilcoxon signed rank test rejects the hypothesis that type 1 subjects play the dominant strategy of 17 in five out of ten periods (periods 1, 2, 3, 7 and 8), but this test never rejects the null hypothesis that subjects on average play the dominant strategy of 16 (two-tailed test, five-percent significance level). Similarly, this nonparametric test rejects the hypothesis that type 2 subjects play the dominant strategy of 12 in eight out of ten periods (periods 1, 2, 3, 5, 6, 7, 8 and 9), but this test never rejects the null hypothesis that subjects on average play the dominant strategy of 13.

These Treatment $P$ results lead to the following observations:

\section{Observation 1:}

(a) The frequency of dominant strategy equilibria was $50 \%$ across all periods in Treatment $P$.

(b) Subjects played Pareto-dominated dominant strategy equilibria about twice as frequently as Pareto-superior dominant strategy equilibria in Treatment $P$.

(c) The data do not reject the hypothesis that subjects play a dominant strategy on average for either type in any period in Treatment $P$. 
(d) Almost all (98\%) of the observed Nash equilibria other than the dominant strategy equilibria were good Nash equilibria that recommended funding of the public good.

\subsection{Treatment S}

A unique dominant strategy equilibrium exists in Tables 3 and 4: 13 for type 1 and 18 for type 2. Notice that there are no other Nash equilibria. Thus, even though the dominant strategy is not strictly dominant, the implementation is secure.

Figure 6 shows the frequency distribution of all data in Treatment S. The maximum frequency pair was the dominant strategy equilibrium $(13,18)$ with 146 of the 180 outcomes. Pairs played no other single outcome more than 4 times.

Figure 6 is around here

We conducted period by period tests of the hypothesis that the mean number equals the dominant strategy (13 for type 1 and 18 for type 2). A Wilcoxon signed rank test never rejects the dominant strategy equilibrium hypothesis for any type in any period.

Summarizing the above results, we have the following:

\section{Observation 2:}

(a) The frequency of dominant strategy equilibrium was $81 \%$ across all periods in Treatment $S$.

(b) The data do not reject the hypothesis that subjects choose the dominant strategy on average for either type in any period in Treatment $S$.

\subsection{Comparing the Two Mechanisms}

Here we compare the frequency that subjects play dominant strategies and that pairs implement dominant strategy equilibria in the two mechanisms. Recall that an 
advantage of our experimental design is that we can compare these two mechanisms while holding constant their complexity. We did not present to subjects any explanation on the rules of a mechanism, and instead we simply used payoff tables to explain the relationship between choices and outcomes.

Figure 7 displays the rates that subjects play dominant strategies separately for all periods. Individuals are more likely to play dominant strategies in Treatment $S$ than in Treatment $P$ according to Fisher's exact test in 7 out of 10 periods (periods 2, 6, 7, 8 and 9 at the $5 \%$ significance level, and periods 4 and 5 at the $10 \%$ significance level). A more powerful parametric test is possible by pooling the data across periods. Since individual subjects contribute an observation for each period it is appropriate to model the panel nature of the data. We do this with a subject random effect specification for the error term. Column 1 of Table 5 reports a probit model of the likelihood that the subject selects a dominant strategy. The positive and significant dummy variable for the mechanism treatment indicates that subjects are more likely to play a dominant strategy in the secure mechanism. $^{8}$

Figure 7 and Table 5 are around here

Figure 8 shows that the differences in the individual dominant strategy rates are magnified for the pair rates. Pairs are more likely to play a dominant strategy equilibrium in Treatment $S$ according to Fisher's exact test in 8 out of 10 periods (periods 2, 4, 6, 7, 8

\footnotetext{
${ }^{8}$ Recall that subjects also indicated the reasons for their choices on their record sheets and in a postexperiment questionnaire. We reviewed their responses and found that more individual subjects provided explanations that were clearly identifiable as dominant strategy arguments (e.g., "This is the highest payoff
} 
and 9 at the $5 \%$ significance level, and periods 3 and 5 at the $10 \%$ significance level).

Column 2 of Table 5 reports a probit model of the likelihood that pairs play a dominant strategy equilibrium, pooling across periods. A random subject effect specification is not possible since the composition of the individuals in each pair changes each period. But we include a dummy variable for the Purdue sessions to capture any (fixed effect) differences across sessions, and this variable is not significantly different from zero. The mechanism treatment dummy variable is highly significant, however, indicating the substantially greater frequency of dominant strategy equilibrium play in Treatment S. Recall that neither Treatment $S$ nor Treatment $\mathrm{P}$ have strictly dominant strategies, but only Treatment S involve a secure mechanism.

Figure 8 is around here

Summarizing the above results, we have the following:

\section{Observation 3:}

(a) Individuals play dominant strategies significantly more frequently in Treatment $S$ than in Treatment $P$.

(b) Pairs implement dominant strategy equilibria significantly more frequently in Treatment $S$ than in Treatment $P$.

\section{Conclusion}

Motivated by the recent theoretical notion of secure implementation introduced in Saijo, Sjöström and Yamato (2003), this paper presents an experimental study of the

column no matter what the other person chooses.") in Treatment S (23 individuals) than in Treatment P (13 individuals). This difference is statistically significant according to Fisher's exact test ( $p$-value=0.021). 
pivotal mechanism and a Groves-Clarke mechanism with single-peaked preferences. Both mechanisms are strategy-proof since they implement truth-telling as dominant strategy equilibria. Only the pivotal mechanism has other Nash equilibria that differ from the dominant strategy equilibria, however. Although the design simplifies both mechanisms equally with payoff tables, players adopted dominant strategies significantly less often in the pivotal mechanism.

This experiment illustrates how a mechanism that is not secure may not yield the desired outcome. Indeed, in the non-secure mechanism the players failed to use their dominant strategies about half of the time. This did not have negative welfare implications, because the public good was anyway funded $98 \%$ of the time. We believe that this outcome was fortuitous, and that there is no reason in general why players who do not play their dominant strategies will end up funding the public good in the right amount in a non-secure mechanism. In contrast, we are optimistic about the performance of secure mechanisms.

We believe that this point is relevant for practical mechanism design. An obvious application is the second price (Vickrey) auction. For certain information conditions - most clearly in a complete information setting - other "bad" Nash equilibria exist in this auction that do not correspond to the (efficient) dominant strategy, truth-telling equilibrium. Most proponents of this auction institution have not acknowledged this shortcoming. Before making predictions regarding how this institution might perform in the field, it would be valuable to conduct laboratory experiments with the information conditions that admit these other inefficient Nash equilibria. We suspect that the second price auction and many other strategy-proof mechanisms may not function as elegantly as designed on the theorist's blackboard, due in part to the frequent existence of non-dominant strategy Nash equilibria. 


\section{Appendix A: Experiment Instructions}

\section{$\underline{\text { Instructions }}$}

This is an experiment in the economics of strategic decision making. Various agencies have provided funds for this research. If you follow the instructions and make appropriate decisions, you can earn an appreciable amount of money. At the end of today's session, you will be paid in private and in cash.

\section{Overview}

In this experiment you will choose a number in each period. You will be paired with one other person each period. The other person will also choose a number simultaneously. Your payoff is determined by the number you choose as well as the number the other person chooses. You can see how much your payoff is by looking at your payoff table. However, your payoff table is different from the payoff table the other person has. An experimenter will choose the person you are paired with from the other participants at random, and the person you are paired with will change each period. You will never be paired with the same person more than once.

This experiment consists of 10 periods. Your earnings are the sum of your payoffs over all 10 periods.

In this experiment, please remember that you cannot talk to anyone but the experimenter. If there is any other talking, the experiment will be stopped at that point. If you have any questions, please ask an experimenter.

First, please confirm the following items on your desk.

- Instructions (this set of papers) - Pencil or pen

- Payoff Table for Practice · · Record Sheet for Practice

\section{Practice}

Please look at the "Payoff Table for Practice." Your payoff table is different from the payoff table of the other people you will be paired with in the actual experiment. However, everyone has the same payoff table in these practice examples. 
You will choose one integer number from 1 to 25 . Suppose that the number you choose is "18". At the time you choose your number, you do not know which number the other person chooses.

Please write the number "18" into the column of "The Number You Chose" in the "Record Sheet for Practice."

In the actual experiment you will also type the number you chose on your computer. The computer will transmit your choice to the person you are paired with for the period. In the practice examples, we'll skip this part. Moreover, in the actual experiment, please fill out why you chose that number into the column of the "Reason for Your Decision" in the record sheet. In practice, we skip this part, too.

Suppose that the person you are paired with also chose "18" in this practice example. Please look at the payoff table. Your payoff is " 150 " when the number you chose is " 18 " and the number the other person chose is " 18 ". Your earnings in this period are equal to the value of your payoff, that is, 150 cents. Please write " 18 " into the column of "The Number the Other Person Chose" and "150" into the column of "Your Payoff" in the "Record Sheet for Practice" in the Period 1 row.

\section{Payoff Table for Practice}

The number you choose

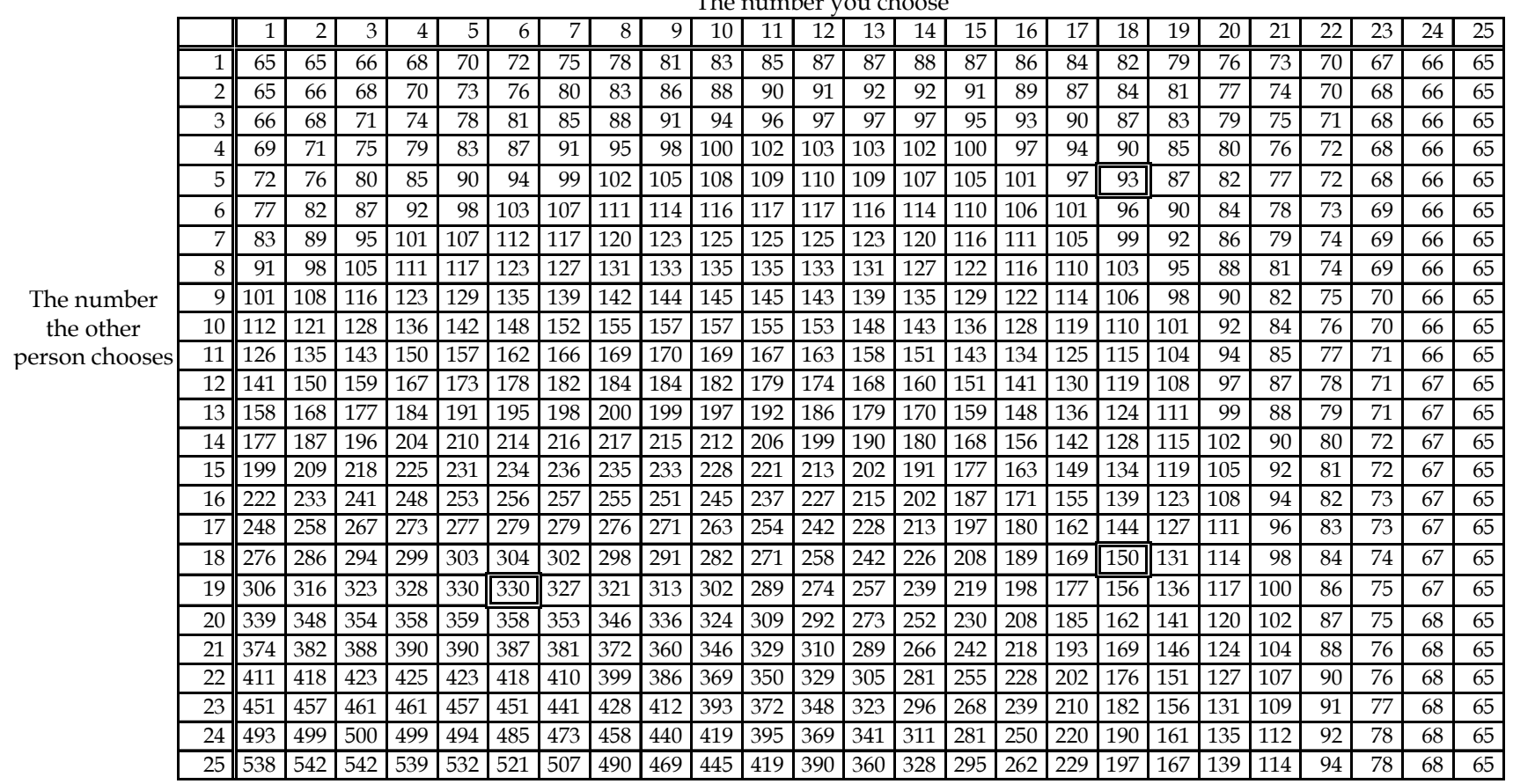


Let us take another example for the second practice period. Suppose you again chose 18. Write this in "The Number You Chose" column for Period 2. But for this example suppose that the person you are paired with chose " 5 " rather than " 18 ". Then your payoff is 93 cents in this period. Please write " 5 " into the column of "The Number the Other Person Chose" and "93" into the column of "Your Payoff."

Finally, let us go on to a third practice period example. Suppose that you chose "6". Write this in Period 3 on your record sheet. Suppose that the person you are paired with chose "19". Then your payoff is 330 cents in this period. Please write "19" into the column of "The Number the Other Person Chose" and "330" into the column of "Your Payoff."

The sum of your payoffs for these three practice periods is $150+93+330=573$. Please write " 573 " into the column of "the Sum of Your Payoffs." This is only practice so you will not be paid this amount.

If you have any questions, please raise your hand.

\section{The Actual Experiment}

First, please pass the "Payoff Table for Practice" and the "Record Sheet of Practice" back to the experimenter now. Next, we will distribute your payoff table and record sheet for the actual experiment.

Your payoff table is different from the payoff table of the people you will be paired with. You will have 10 minutes to look at the payoff table to understand it before we begin the experiment.

Are there any questions? 


\section{Appendix B: Comparison of the Japanese and American Sessions Results}

\section{B.1 Treatment $\mathbf{P}$}

Average choices, Type 1: The data do not reject the null hypothesis that the average offers are equal in the two countries in any of the 8 individual periods ( $t$-test) at $10 \%$ significance level. The data reject this same null hypothesis in two periods at the $10 \%$ level (only), periods 4 and 5, using a nonparametric Wilcoxon test. When pooling the data across periods and comparing the choices across countries using a panel data regression (with individual subjects as the random effect for the error term), the data do not reject the null hypothesis that offers are equal in the two countries $(t=1.312)$.

Average choices, Type 2: The data do not reject the null hypothesis that the average offers are equal in the two countries in any of the 8 individual periods ( $t$-test) at $10 \%$ significance level. The data reject this same null hypothesis in one of the 8 periods (period 1) at the $10 \%$ level (only) using a nonparametric Wilcoxon test. When pooling the data across periods and comparing the choices across countries using a panel data regression (with individual subjects as the random effect for the error term), the data do not reject the null hypothesis that offers are equal in the two countries $(t=0.609)$.

Rate playing dominant strategy, pooling over types: According to Fisher's exact test, the data reject the null hypothesis that the rate subjects play a dominant strategy is equal in the two countries in one of the 8 individual periods (period 1), at the $5 \%$ significance level. Pooling the data across periods using a panel data regression (with individual subjects as the random effect for the error term) in a probit model of the likelihood that subjects play a dominant strategy, we do reject the null hypothesis that there is no difference across countries $(t=2.001)$. But this is due to the significant difference in the first period only; 
estimating this same model after dropping the first period, we do not reject the null hypothesis of no differences across countries $(t=1.559)$.

\section{B.2 Treatment S}

Average choices, Type 1: The data reject the null hypothesis that the average offers are equal in the two countries in only one (period 1$)$ of the 8 individual periods ( $t$-test) at the $10 \%$ significance level. The data reject this same null hypothesis in only the same one period (period 1) at the $10 \%$ level using a nonparametric Wilcoxon test. When pooling the data across periods and comparing the choices across countries using a panel data regression (with individual subjects as the random effect for the error term), the data do not reject the null hypothesis that offers are equal in the two countries $(t=1.774)$.

Average choices, Type 2: The data do not reject the null hypothesis that the average offers are equal in the two countries in any of the 8 individual periods at $10 \%$ significance level, using either a $t$-test of a nonparametric Wilcoxon test. When pooling the data across periods and comparing the choices across countries using a panel data regression (with individual subjects as the random effect for the error term), the data do not reject the null hypothesis that offers are equal in the two countries $(t=1.295)$.

Rate playing dominant strategy, pooling over types: According to Fisher's exact test, the data do not reject the null hypothesis that the rate subjects play a dominant strategy is equal in the two countries in any of the 8 individual periods at the $10 \%$ significance level. Pooling the data across periods using a panel data regression (with individual subjects as the random effect for the error term) in a probit model of the likelihood that subjects play a dominant strategy, we do not reject the null hypothesis of no differences across countries $(t=0.029)$. 


\section{B.3 Summary}

Of the 32 (=2 types * 2 treatments * 8 periods) period-by-period tests comparing individual choices across sites, we reject the null of no country difference in 1 out of $32(t$ test) and 3 out of 32 (Wilcoxon test) at the 10\% significance level. We expect about 10\% rejections (about 3 out of 32 ) at the $10 \%$ significance level if the null is true, exactly as we observe. This leads us to the conclusion that there are no country differences. The panel data regressions pooling across periods confirm this conclusion.

Of the 16 (=2 treatments * 8 periods) tests that pool across types, we reject the null that subjects play the dominant strategy at different rates across countries in 1 out of the 16 cases. The panel data regressions confirm that the only difference across sites is in period 1 of treatment $P$. 


\section{References}

Attiyeh, G., Franciosi, R. and Isaac, R. M. (2000). “Experiments with the Pivotal Process for Providing Public Goods," Public Choice, 102, 95-114.

Aumann, R. and Brandenburger, B. (1995). “Epistemic Conditions for Nash Equilibrium," Econometrica, 63, 1161-1180.

Binmore, K.G., Gale, J. and Samuelson, L. (1995). “Learning to be Imperfect: the Ultimatum Game," Games and Economic Behavior, 8, 56-90.

Cabrales A. and Ponti G. (2000). “Implementation, Elimination of Weakly Dominated Strategies and Evolutionary Dynamics," Review of Economic Dynamics, 3, 247-282.

Cassady, R. (1967). Auctions and Auctioneering. Berkeley, CA: University of California Press.

Chen, Y. (2003). "An Experimental Study of the Serial and Average Cost Pricing Mechanisms," Journal of Public Economics, forthcoming.

Clarke, E. H. (1971). “Multipart Pricing of Public Goods,” Public Choice, 2, 19-33.

Coppinger, V.M., Smith, V.L. and Titus, J.A. (1980). “Incentives and Behavior in English, Dutch and Sealed-Bid Auctions," Economic Inquiry, 18, 1-22.

Dorsey, R. and Razzolini, L. (1999). “An Experimental Evaluation of the Serial Cost Sharing Rule," mimeo, University of Mississippi.

Fischbacher, U. (1999). “z-Tree. Toolbox for Readymade Economic Experiments," IEW Working paper 21, University of Zurich.

Garratt, R., Walker, M. and Wooders, J. (2002). “Experienced Bidders in Online SecondPrice Auctions," mimeo.

Gibbard, A. (1973). “Manipulation of Voting Schemes,” Econometrica, 41, 587-601.

Green, J. R. and Laffont, J.-J. (1979). Incentives in Public Decision Making. Amsterdam: North- Holland.

Groves, T. (1973). “Incentives in Teams,” Econometrica, 41, 617-31.

Harstad, R. M. (2000). “Dominant Strategy Adoption and Bidders' Experience with Pricing Rules," Experimental Economics, 3, 261-280. 
Kagel, J. H., Harstad, R. M. and Levin, D. (1987). "Information Impact and Allocation Rules in Auctions with Affiliated Private Values: A Laboratory Study," Econometrica, 55, 1275-1304.

Kagel, J. H. and Levin, D. (1993). “Independent Private Value Auctions: Bidder Behavior in First- Second- and Third-Price Auctions with Varying Number of Bidders," Economic Journal, 103, 868-879.

Kawagoe, T. and Mori, T. (2001). “Can the Pivotal Mechanism Induce Truth-Telling? An Experimental Study," Public Choice, 108, 331-354.

Maskin, E. (1979). “Incentive Schemes Immune to Group Manipulation,” mimeo.

Roth, A. E. and Ockenfels, A. (2002). "Last Minute Bidding and the Rules for Ending Second-Price Auctions: Evidence from eBay and Amazon Auctions on the Internet," American Economic Review, 92, 1093-1103.

Saijo, T., Sjöström , T, and Yamato, T. (2003). “Secure Implementation: Strategy-Proof Mechanisms Reconsidered," mimeo.

Vickrey, W. (1961). "Counterspeculation, Auctions, and Competitive Sealed Tenders," Journal of Finance 16, 8-37.

Yamato, T. (1993). “Double Implementation in Nash and Undominated Nash Equilibria," Journal of Economic Theory, 59, 311-323. 


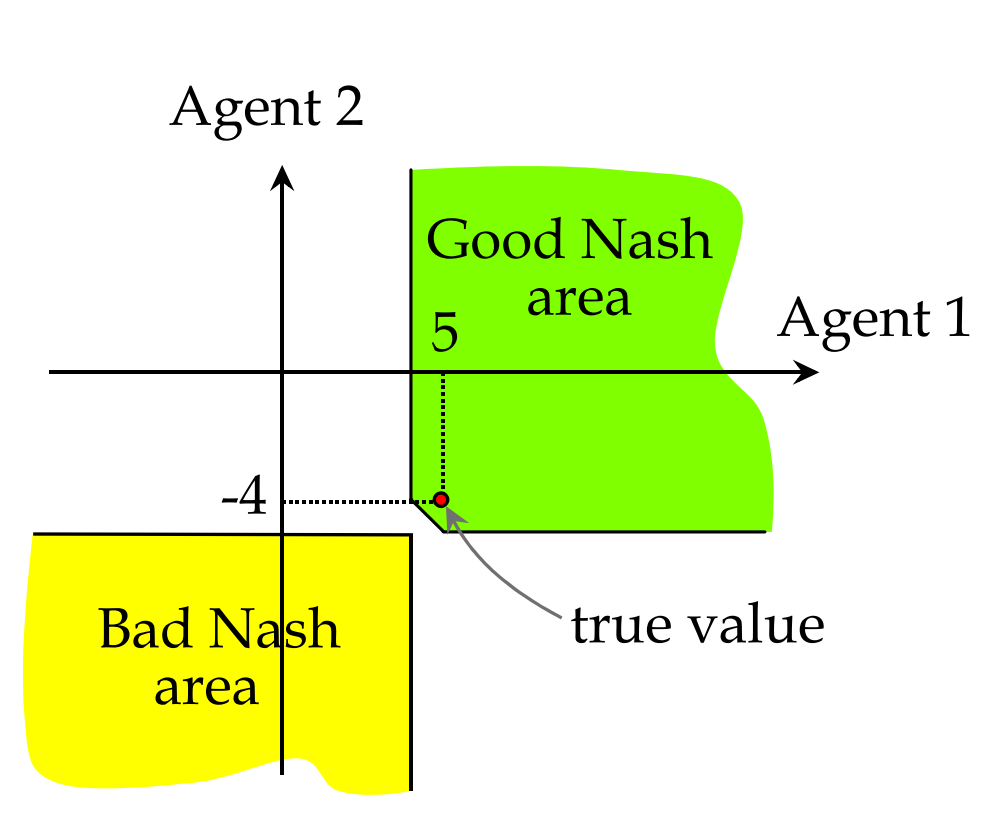

(a)

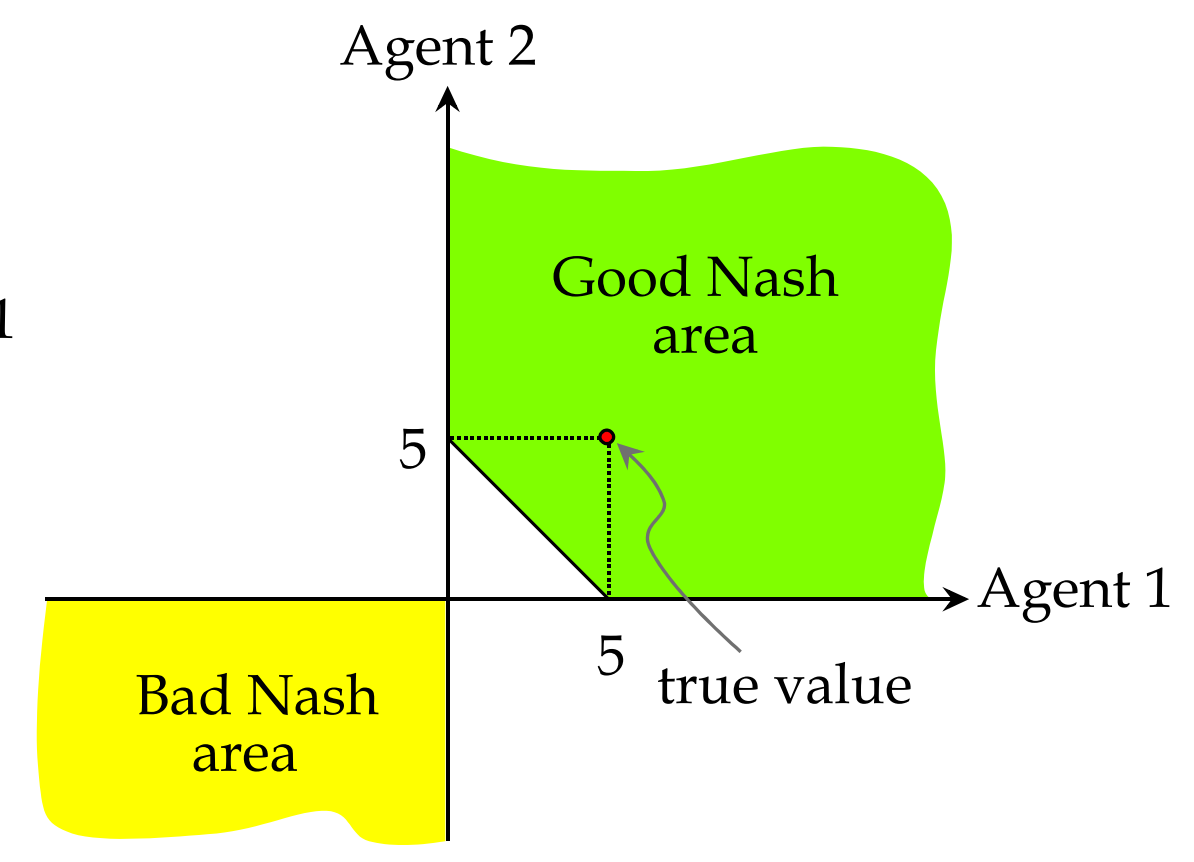

(b)

Figure 1: Equilibria of the Pivotal Mechanism 


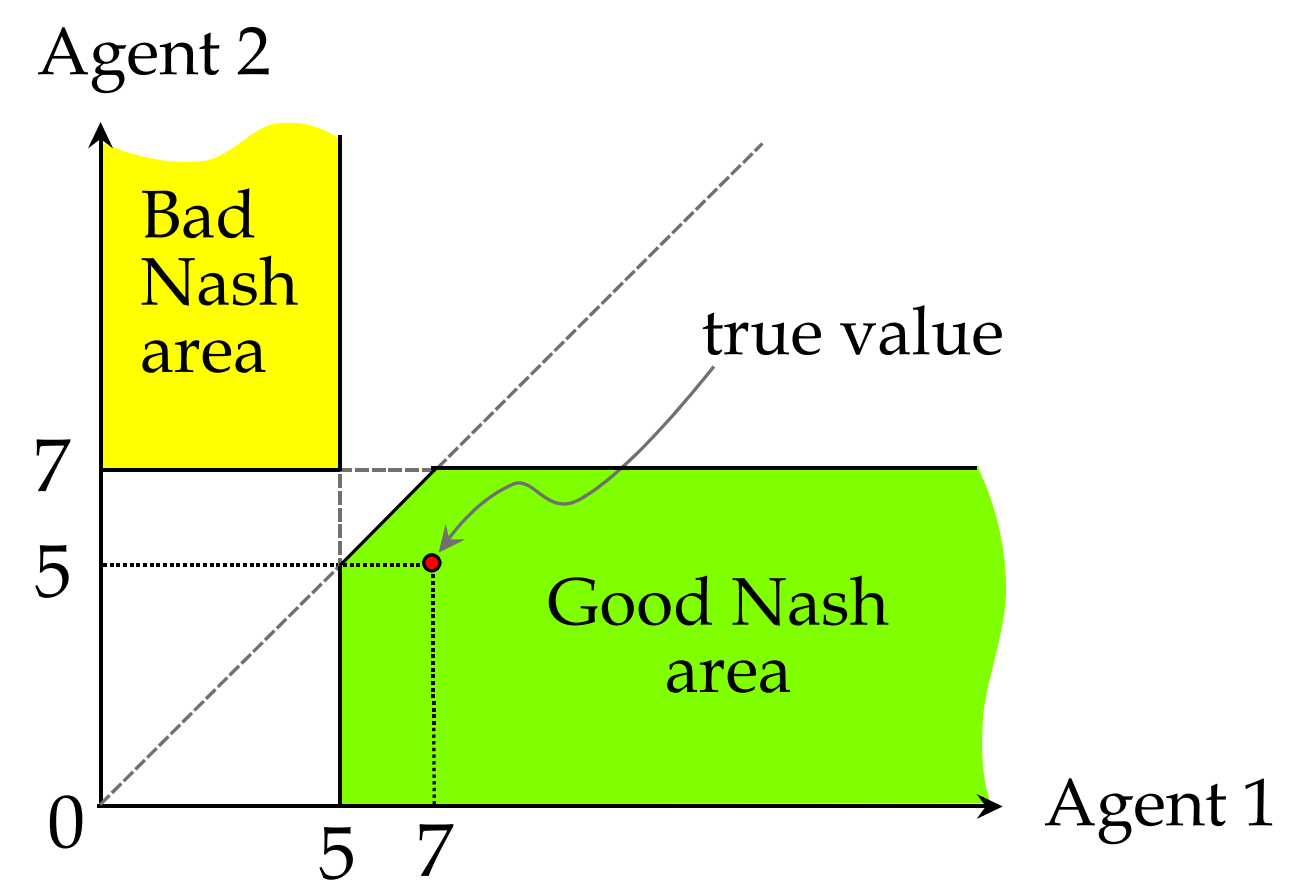

Figure 2: Equilibria of the Second Price Auction 


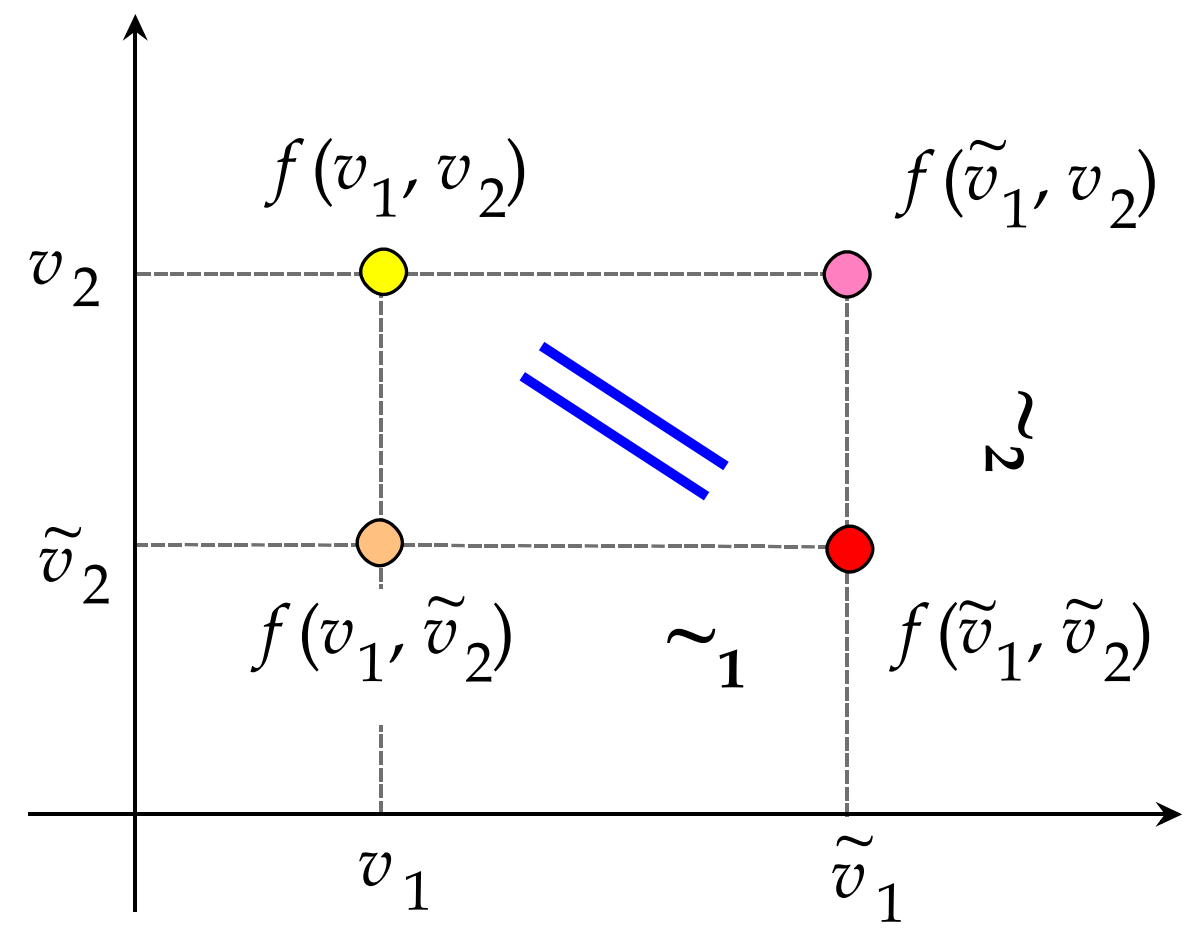

Figure 3: Rectangular Property 


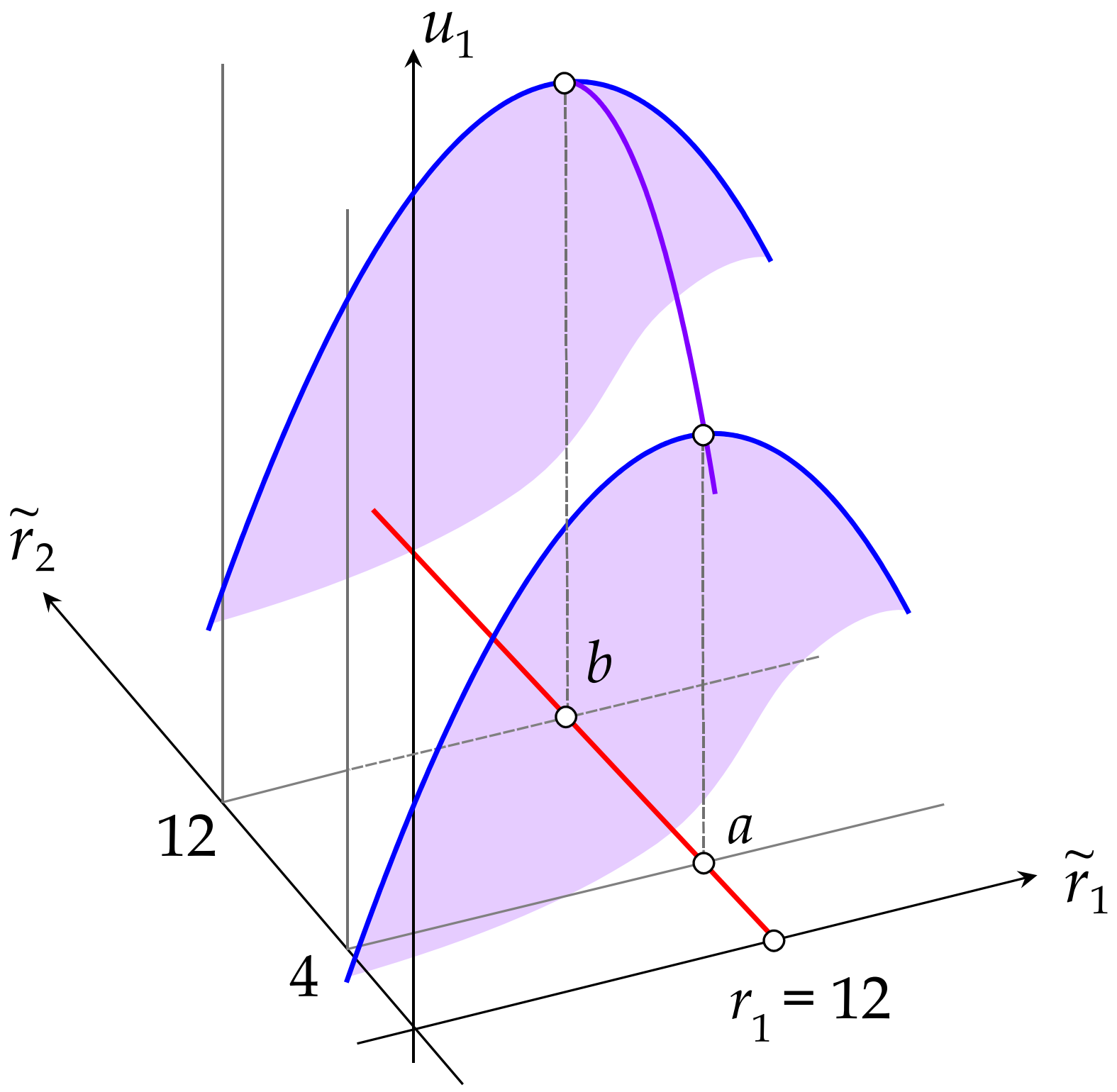

Figure 4: Payoff function of a Groves Mechanism with Single-Peaked Preferences 


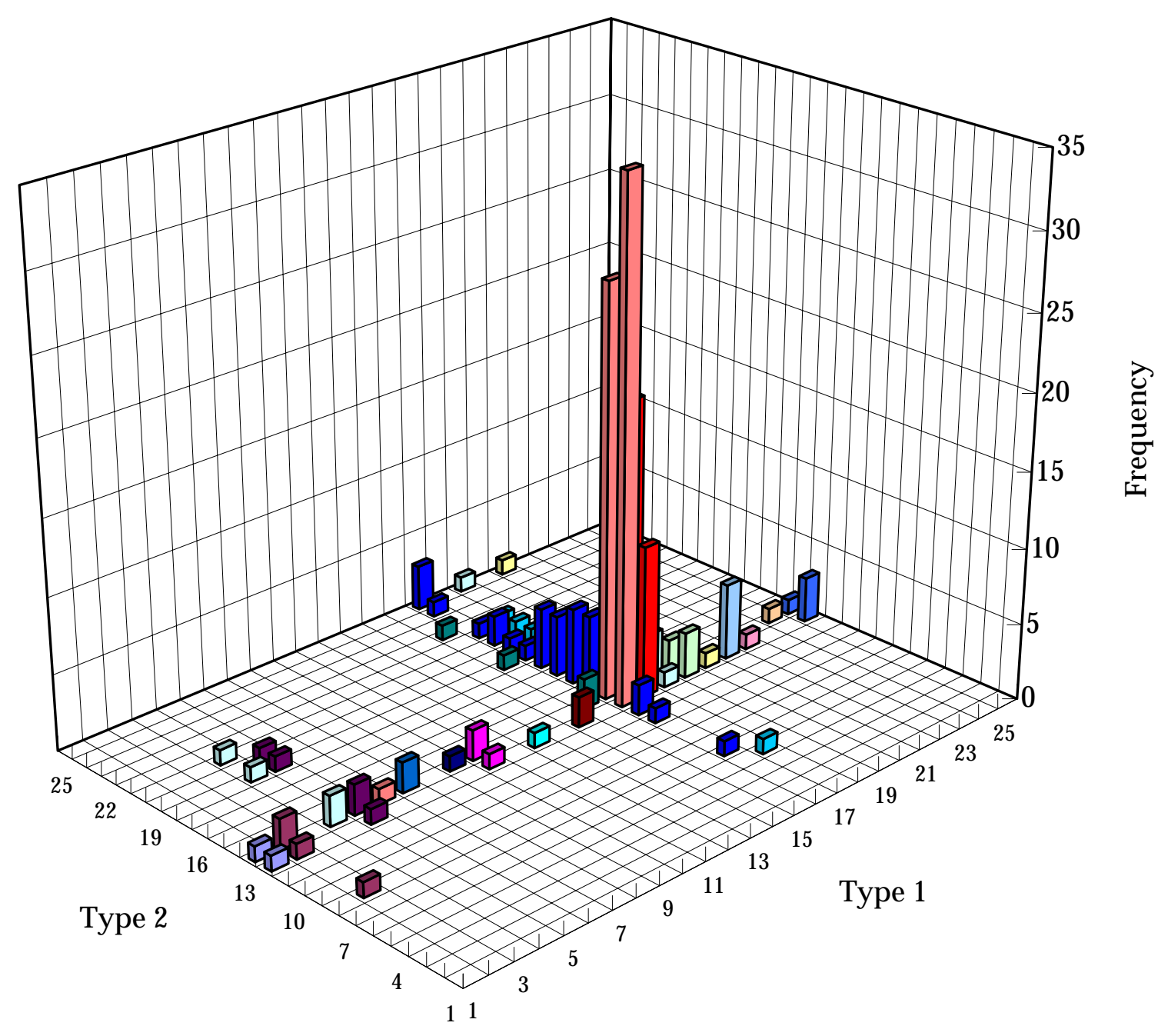

Figure 5: Treatment P -- All Pairs Choices 


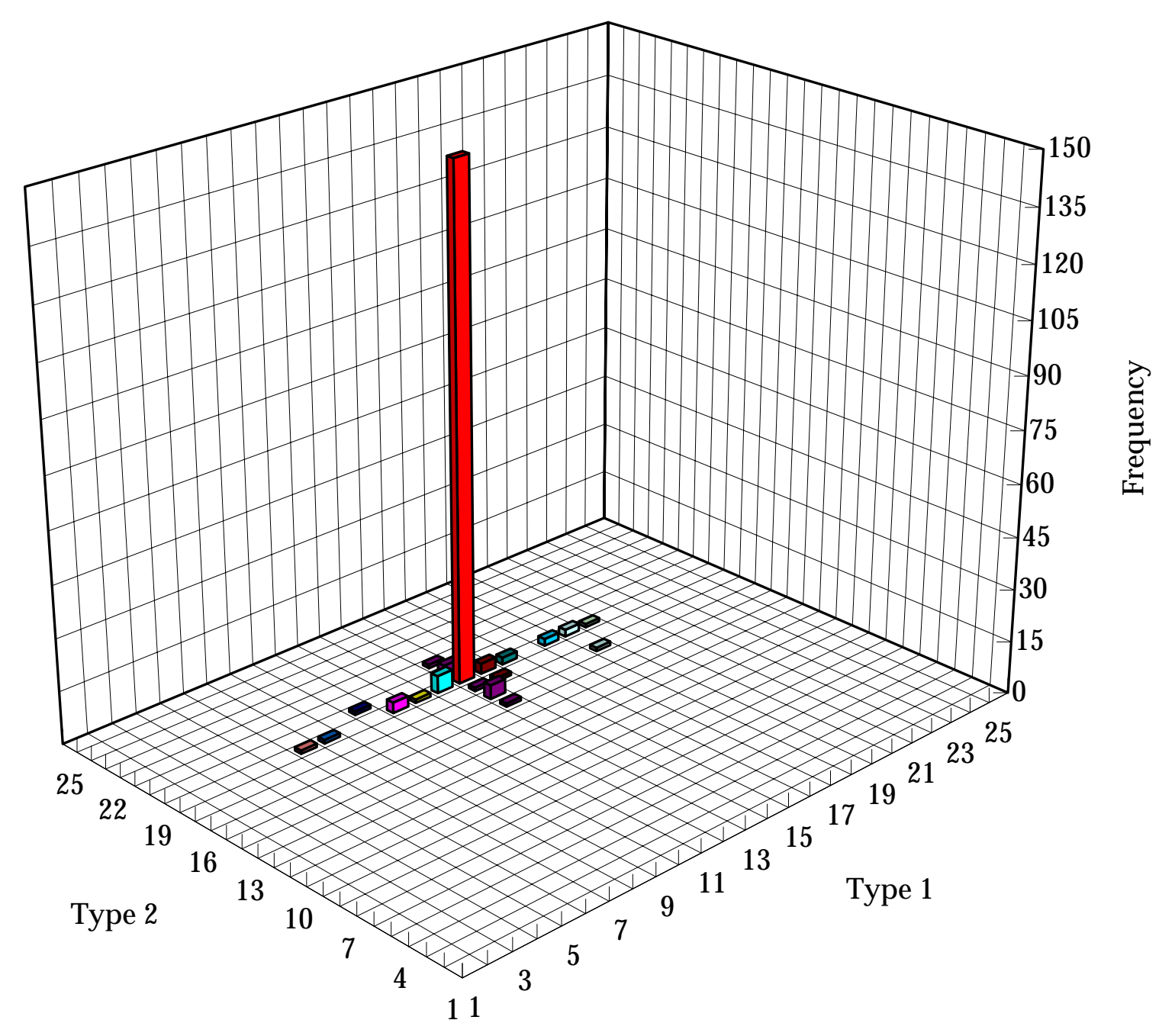

Figure 6: Treatment S -- All Pairs Choices 


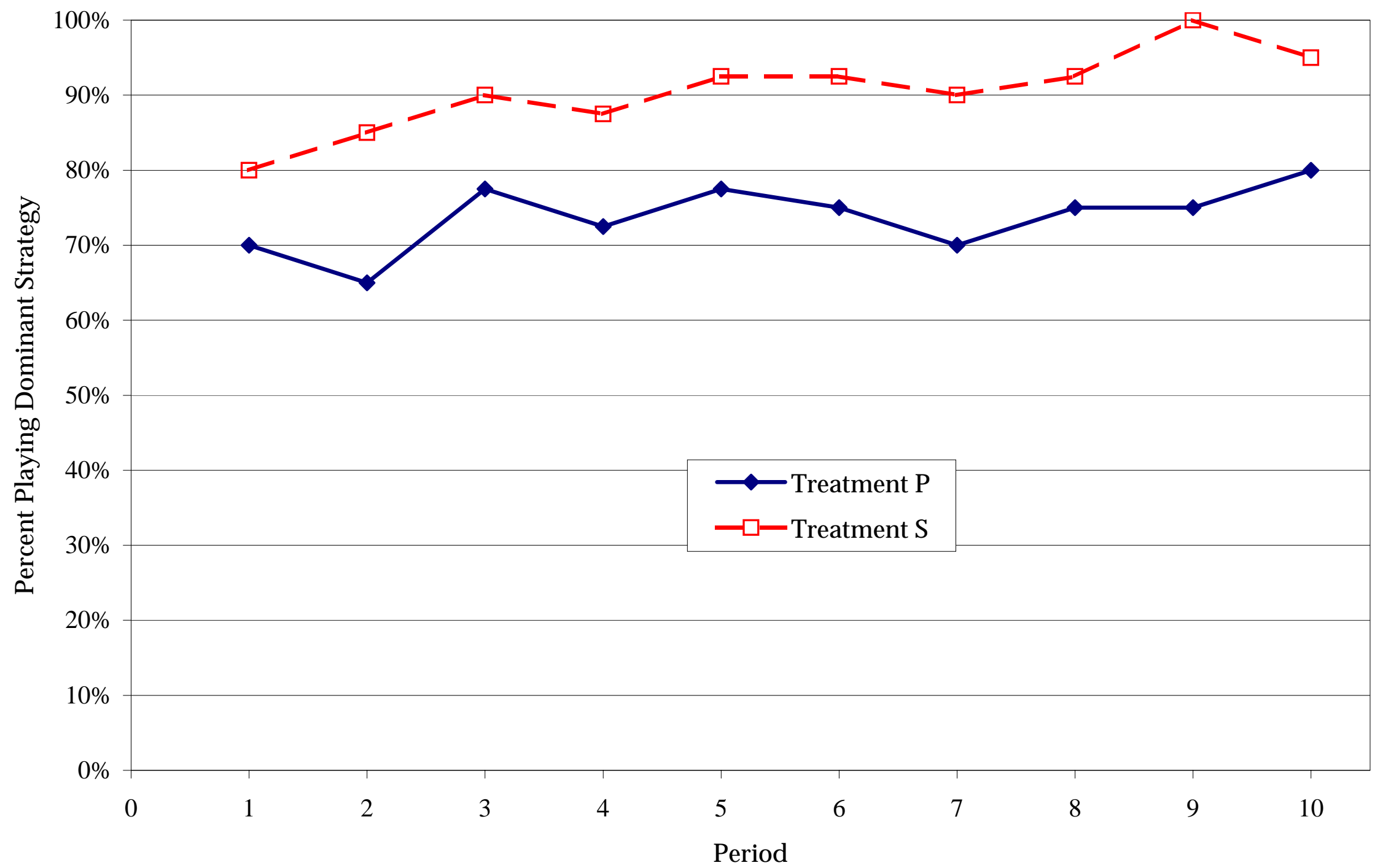

Figure 7: Rates that Individuals Play Dominant Strategies 


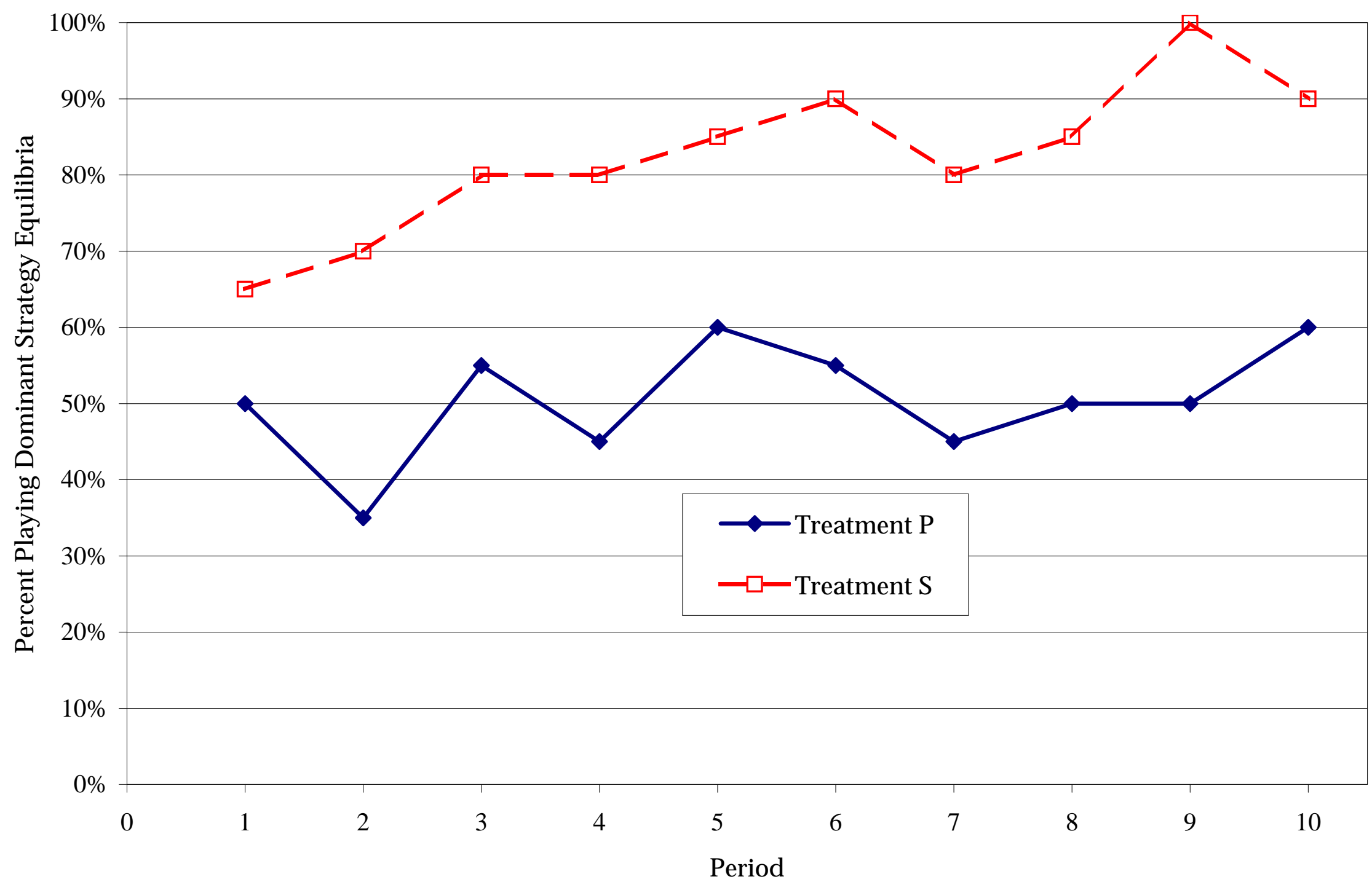

Figure 8: Rates that Pairs Play Dominant Strategy Equilibria 


\section{A ppendix C: Payoff Tables for the Pivotal and Groves Mechanisms}

$\widetilde{v}_{1} \quad$ type l's reported value

\begin{tabular}{|c|c|c|c|c|c|c|c|c|c|c|c|c|c|c|c|c|c|c|c|c|c|c|c|c|c|}
\hline & 22 & 21 & 20 & -19 & 18 & \begin{tabular}{|c|} 
\\
\end{tabular} & -16 & \begin{tabular}{|c|} 
\\
\end{tabular} & \begin{tabular}{|c|}
-14 \\
\end{tabular} & \begin{tabular}{|c|}
-13 \\
\end{tabular} & \begin{tabular}{|l|}
-12 \\
\end{tabular} & \begin{tabular}{l|l}
-11 \\
\end{tabular} & -10 & -9 & -8 & -7 & \begin{tabular}{l|}
-6 \\
\end{tabular} & \begin{tabular}{l|}
-5 \\
\end{tabular} & \begin{tabular}{|l|}
-4 \\
\end{tabular} & \begin{tabular}{l|}
-3 \\
\end{tabular} & \begin{tabular}{l|}
-2 \\
\end{tabular} & \begin{tabular}{l|}
-1 \\
\end{tabular} & 이 & 1 & \\
\hline-4 & 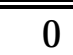 & & & 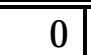 & & \begin{tabular}{|l|}
0 \\
\end{tabular} & 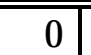 & 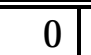 & 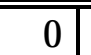 & 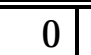 & 1 & 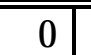 & & & & & & & & & & & & & \\
\hline & & & & & & & & & & & & 0 & & & & & & & & & & & & & \\
\hline-2 & c & 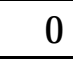 & & c & $\mathrm{c}$ & c & 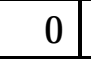 & 0 & 0 & 0 & 0 & 0 & & & & & & & & & & & & & \\
\hline-1 & 0 & ( & & & & $c$ & ( & 0 & 0 & $c$ & 0 & 0 & & & & & & & & & & & & & \\
\hline 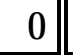 & $\mathrm{c}$ & & & & & 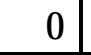 & & 0 & 0 & 0 & 0 & 0 & & & & & & & & & & & -6 & 6 & 6 \\
\hline 1 & -1 & -1 & -1 & -1 & -1 & -1 & -1 & -1 & -1 & -1 & -1 & -1 & -1 & & - & & & & & & & 6 & -6 & & -6 \\
\hline 2 & -2 & -2 & -2 & \begin{tabular}{|c|}
-2 \\
\end{tabular} & -2 & \begin{tabular}{l|}
-2 \\
\end{tabular} & \begin{tabular}{l|} 
\\
\end{tabular} & -2 & -2 & -2 & -2 & -2 & -2 & -2 & -2 & -2 & 7 & -2 & -2 & 7 & -6 & -6 & -6 & & - \\
\hline 3 & -3 & -3 & -3 & \begin{tabular}{|l|}
-3 \\
\end{tabular} & -3 & \begin{tabular}{|l|}
-3 \\
\end{tabular} & -3 & -3 & -3 & -3 & -3 & -3 & -3 & & -3 & & & -3 & & -6 & & & & & -6 \\
\hline 4 & -4 & -4 & -4 & -4 & -4 & -4 & -4 & -4 & -4 & -4 & -4 & -4 & -4 & & -2 & & -4 & -4 & & c & & & & & -6 \\
\hline 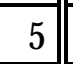 & -5 & -5 & -5 & -5 & -5 & \begin{tabular}{c|}
-5 \\
\end{tabular} & -5 & -5 & -5 & -5 & -5 & -5 & -5 & -5 & -5 & -5 & -5 & - & -6 & -6 & 6 & 6 & & & 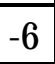 \\
\hline 6 & -6 & -6 & -6 & -6 & -6 & -6 & -6 & -6 & -6 & -6 & -6 & -6 & -6 & -6 & -6 & -6 & 0 & -6 & -6 & -6 & -6 & -6 & -6 & & -6 \\
\hline 7 & -7 & -7 & -7 & -7 & -7 & \begin{tabular}{|c|}
-7 \\
\end{tabular} & -7 & -7 & -7 & -7 & -7 & -1 & -7 & & -7 & & -6 & -6 & -6 & -6 & & & & & -6 \\
\hline 8 & -8 & -8 & -8 & -8 & -8 & -8 & -8 & -8 & -8 & -8 & -8 & -8 & -8 & $-\varepsilon$ & 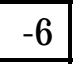 & & $-t$ & -6 & -6 & -6 & -6 & 6 & 6 & & - \\
\hline 9 & -9 & -9 & -9 & -9 & -9 & -9 & -9 & -9 & \begin{tabular}{|c|}
-9 \\
\end{tabular} & -9 & -9 & -9 & -9 & -6 & -6 & -6 & -6 & -0 & -6 & \begin{tabular}{|c|}
-6 \\
\end{tabular} & \begin{tabular}{|c|}
-6 \\
\end{tabular} & \begin{tabular}{|c|}
-6 \\
\end{tabular} & -6 & -6 & -6 \\
\hline 10 & -10 & 0 & 10 & 10 & -10 & -10 & -10 & -10 & -10 & -10 & -10 & -10 & -6 & & 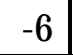 & & 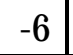 & -6 & -6 & -6 & 6 & $f$ & & & -6 \\
\hline 1. & \begin{tabular}{|l|}
-11 \\
\end{tabular} & -11 & -11 & -11 & -11 & -11 & -11 & \begin{tabular}{|c|}
-11 \\
\end{tabular} & \begin{tabular}{|c|}
-11 \\
\end{tabular} & \begin{tabular}{|c|}
-11 \\
\end{tabular} & -11 & -6 & -6 & & -6 & & & & & -6 & & & & & -6 \\
\hline 12 & -12 & -12 & -12 & -12 & -12 & -12 & -12 & -12 & -12 & -12 & -6 & -6 & -6 & -6 & + & -6 & - & -6 & -6 & -6 & -6 & -6 & -6 & -6 & -6 \\
\hline 13 & -13 & -13 & -13 & -13 & -13 & -13 & -13 & -13 & -13 & -6 & -6 & -6 & -6 & -6 & -6 & -6 & -6 & -6 & $\mid-6$ & -6 & \begin{tabular}{|c|}
-6 \\
\end{tabular} & \begin{tabular}{|c|}
-6 \\
\end{tabular} & \begin{tabular}{|c|}
-6 \\
\end{tabular} & -6 & -6 \\
\hline 14 & -14 & -14 & -14 & -14 & -14 & -14 & -14 & -14 & -6 & -6 & -6 & -6 & 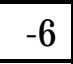 & & -6 & & -0 & \begin{tabular}{|c|}
-6 \\
\end{tabular} & -6 & -6 & 4 & & -6 & & 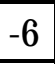 \\
\hline 15 & -15 & -15 & -15 & -15 & -15 & -15 & -15 & -6 & -6 & -6 & -6 & -6 & -6 & -6 & -0 & -6 & $-c$ & -6 & -0 & -6 & -0 & -0 & -0 & -0 & -0 \\
\hline 16 & -16 & -16 & -16 & -16 & -16 & -16 & -6 & -6 & -6 & -6 & -6 & -6 & -6 & -6 & -6 & -6 & 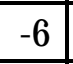 & \begin{tabular}{|c|}
-6 \\
\end{tabular} & \begin{tabular}{|c|}
-6 \\
\end{tabular} & -6 & $\begin{array}{ll}-6 \\
\end{array}$ & -6 & -6 & -6 & -6 \\
\hline 17 & -17 & -17 & -17 & -17 & -17 & \begin{tabular}{|c|}
-6 \\
\end{tabular} & \begin{tabular}{|c|}
-6 \\
\end{tabular} & \begin{tabular}{|c|}
-6 \\
\end{tabular} & \begin{tabular}{|c|}
-6 \\
\end{tabular} & -6 & -6 & -6 & -6 & -6 & -6 & -6 & -6 & -6 & $\mid-6$ & $\mid-6$ & \begin{tabular}{|c|}
-6 \\
\end{tabular} & \begin{tabular}{|c|}
-6 \\
\end{tabular} & \begin{tabular}{|c|}
-6 \\
\end{tabular} & -0 & -0 \\
\hline 18 & -18 & -18 & -18 & -18 & $\begin{array}{l}-6 \\
\end{array}$ & \begin{tabular}{l|l}
-6 \\
\end{tabular} & -6 & -6 & -6 & -6 & -6 & -6 & -6 & $-c$ & $-c$ & 4 & -0 & -6 & \begin{tabular}{|c|}
-6 \\
\end{tabular} & \begin{tabular}{|l|}
-6 \\
\end{tabular} & \begin{tabular}{|l|}
-6 \\
\end{tabular} & -6 & 6 & 6 & -6 \\
\hline 19 & -19 & -19 & -19 & \begin{tabular}{|c|}
-6 \\
\end{tabular} & -6 & \begin{tabular}{|c|}
-6 \\
\end{tabular} & \begin{tabular}{|c|}
-6 \\
\end{tabular} & \begin{tabular}{|c|}
-6 \\
\end{tabular} & -6 & -6 & -6 & -6 & -6 & -6 & -6 & -6 & -0 & -6 & -6 & -6 & -6 & -6 & -6 & $-6 \mid$ & -0 \\
\hline 20 & 20 & -20 & -6 & -6 & -6 & -6 & -6 & \begin{tabular}{|c|}
-6 \\
\end{tabular} & \begin{tabular}{|c|}
-6 \\
\end{tabular} & -6 & -6 & -6 & -6 & -6 & -6 & 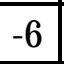 & -6 & -6 & -6 & -6 & -6 & -6 & -6 & -6 & \\
\hline
\end{tabular}

Table C-1. Payoff Table of Type 1 for the Pivotal Mechanism. 
$\widetilde{\nabla}_{2}$ type 2's reported value

\begin{tabular}{|c|c|c|c|c|c|c|c|c|c|c|c|c|c|c|c|c|c|c|c|c|c|c|c|c|c|c|}
\hline \multirow{26}{*}{$\begin{array}{c}\sigma_{1} \\
\text { type 1's } \\
\text { reported } \\
\text { value }\end{array}$} & & -4 & -3 & -2 & -1 & 0 & 1 & 2 & 3 & 4 & 5 & 6 & 7 & 8 & 9 & 10 & 11 & 12 & 13 & 14 & 15 & 16 & 17 & 18 & 19 & 20 \\
\hline & -22 & 0 & 0 & 0 & 0 & 0 & 0 & 0 & 0 & 0 & 0 & 0 & 0 & 0 & 0 & 0 & 0 & 0 & 0 & 0 & 0 & 0 & 0 & 0 & 0 & 0 \\
\hline & -21 & 0 & 0 & 0 & 0 & 0 & 0 & 0 & 0 & 0 & 0 & 0 & 0 & 0 & 0 & 0 & 0 & 0 & 0 & 0 & 0 & 0 & 0 & 0 & 0 & 0 \\
\hline & -20 & 0 & 0 & 0 & 0 & 0 & 0 & 0 & 0 & 0 & 0 & 0 & 0 & 0 & 0 & 0 & 0 & 0 & 0 & 0 & 0 & 0 & 0 & 0 & 0 & -12 \\
\hline & -19 & 0 & 0 & 0 & 0 & 0 & 0 & 0 & 0 & 0 & 0 & 0 & 0 & 0 & 0 & 0 & 0 & 0 & 0 & 0 & 0 & 0 & 0 & 0 & -11 & -11 \\
\hline & -18 & 0 & 0 & 0 & 0 & 0 & 0 & 0 & 0 & 0 & 0 & 0 & 0 & 0 & 0 & 0 & 0 & 0 & 0 & 0 & 0 & 0 & 0 & -10 & -10 & -10 \\
\hline & -17 & 0 & 0 & 0 & 0 & 0 & 0 & 0 & 0 & 0 & 0 & 0 & 0 & 0 & 0 & 0 & 0 & 0 & 0 & 0 & 0 & 0 & -9 & -9 & -9 & -9 \\
\hline & -16 & 0 & 0 & 0 & 0 & 0 & 0 & 0 & 0 & 0 & 0 & 0 & 0 & 0 & 0 & 0 & 0 & 0 & 0 & 0 & 0 & -8 & -8 & -8 & -8 & -8 \\
\hline & -15 & 0 & 0 & 0 & 0 & 0 & 0 & 0 & 0 & 0 & 0 & 0 & 0 & 0 & 0 & 0 & 0 & 0 & 0 & 0 & -7 & -7 & -7 & -7 & -7 & -7 \\
\hline & -14 & 0 & 0 & 0 & 0 & 0 & 0 & 0 & 0 & 0 & 0 & 0 & 0 & 0 & 0 & 0 & 0 & 0 & 0 & -6 & -6 & -6 & -6 & -6 & -6 & -6 \\
\hline & -13 & 0 & 0 & 0 & 0 & 0 & 0 & 0 & 0 & 0 & 0 & 0 & 0 & 0 & 0 & 0 & 0 & 0 & -5 & -5 & -5 & -5 & -5 & -5 & -5 & -5 \\
\hline & -12 & 0 & 0 & 0 & 0 & 0 & 0 & 0 & 0 & 0 & 0 & 0 & 0 & 0 & 0 & 0 & 0 & -4 & -4 & -4 & -4 & -4 & -4 & -4 & -4 & -4 \\
\hline & -11 & 0 & 0 & 0 & 0 & 0 & 0 & 0 & 0 & 0 & 0 & 0 & 0 & 0 & 0 & 0 & -3 & -3 & -3 & -3 & -3 & -3 & -3 & -3 & -3 & -3 \\
\hline & -10 & 0 & 0 & 0 & 0 & 0 & 0 & 0 & 0 & 0 & 0 & 0 & 0 & 0 & 0 & -2 & -2 & -2 & -2 & -2 & -2 & -2 & -2 & -2 & -2 & -2 \\
\hline & -9 & 0 & 0 & 0 & 0 & 0 & 0 & 0 & 0 & 0 & 0 & 0 & 0 & 0 & -1 & -1 & -1 & -1 & -1 & -1 & -1 & -1 & -1 & -1 & -1 & -1 \\
\hline & -8 & 0 & 0 & 0 & 0 & 0 & 0 & 0 & 0 & 0 & 0 & 0 & 0 & 0 & 0 & 0 & 0 & 0 & 0 & 0 & 0 & 0 & 0 & 0 & 0 & 0 \\
\hline & -7 & 0 & 0 & 0 & 0 & 0 & 0 & 0 & 0 & 0 & 0 & 0 & 1 & 1 & 1 & 1 & 1 & 1 & 1 & 1 & 1 & 1 & 1 & 1 & 1 & 1 \\
\hline & -6 & 0 & 0 & 0 & 0 & 0 & 0 & 0 & 0 & 0 & 0 & 2 & 2 & 2 & 2 & 2 & 2 & 2 & 2 & 2 & 2 & 2 & 2 & 2 & 2 & 2 \\
\hline & -5 & 0 & 0 & 0 & 0 & 0 & 0 & 0 & 0 & 0 & 3 & 3 & 3 & 3 & 3 & 3 & 3 & 3 & 3 & 3 & 3 & 3 & 3 & 3 & 3 & 3 \\
\hline & -4 & 0 & 0 & 0 & 0 & 0 & 0 & 0 & 0 & 4 & 4 & 4 & 4 & 4 & 4 & 4 & 4 & 4 & 4 & 4 & 4 & 4 & 4 & 4 & 4 & 4 \\
\hline & -3 & 0 & 0 & 0 & 0 & 0 & 0 & 0 & 5 & 5 & 5 & 5 & 5 & 5 & 5 & 5 & 5 & 5 & 5 & 5 & 5 & 5 & 5 & 5 & 5 & 5 \\
\hline & -2 & 0 & 0 & 0 & 0 & 0 & 0 & 6 & 6 & 6 & 6 & 6 & 6 & 6 & 6 & 6 & 6 & 6 & 6 & 6 & 6 & 6 & 6 & 6 & 6 & 6 \\
\hline & -1 & 0 & 0 & 0 & 0 & 0 & 7 & 7 & 7 & 7 & 7 & 7 & 7 & 7 & 7 & 7 & 7 & 7 & 7 & 7 & 7 & 7 & 7 & 7 & 7 & 7 \\
\hline & 0 & 0 & 0 & 0 & 0 & 8 & 8 & 8 & 8 & 8 & 8 & 8 & 8 & 8 & 8 & 8 & 8 & 8 & 8 & 8 & 8 & 8 & 8 & 8 & 8 & 8 \\
\hline & 1 & -1 & -1 & -1 & 8 & 8 & 8 & 8 & 8 & 8 & 8 & 8 & 8 & 8 & 8 & 8 & 8 & 8 & 8 & 8 & 8 & 8 & 8 & 8 & 8 & 8 \\
\hline & 2 & -2 & -2 & 8 & 8 & 8 & 8 & 8 & 8 & 8 & 8 & 8 & 8 & 8 & 8 & 8 & 8 & 8 & 8 & 8 & 8 & 8 & 8 & 8 & 8 & 8 \\
\hline
\end{tabular}

Table C-2. Payoff Table of Type 2 for the Pivotal Mechanism. 


\begin{tabular}{|c|c|c|c|c|c|c|c|c|c|c|c|c|c|c|c|c|c|c|c|c|c|c|c|c|c|}
\hline & 0 & 1 & 2 & 3 & 4 & 5 & 6 & 7 & 8 & 9 & 10 & 11 & 12 & 13 & 14 & 15 & 16 & 17 & 18 & 19 & 20 & 21 & 22 & 23 & 4 \\
\hline 0 & -144.0 & 32.5 & -122.0 & 12.5 & -104.0 & -96.5 & -90.0 & -84.5 & 80.0 & 76.5 & -74.0 & -72.5 & -72.0 & -72.5 & -74.0 & -76.5 & -80.0 & -84.5 & -90.0 & -96.5 & -104.0 & 112.5 & -122.0 & -132.5 & -144.0 \\
\hline 1 & -132.5 & 21.0 & -110.5 & 01.0 & -92.5 & 85.0 & -78.5 & -73.0 & -68.5 & 65.0 & -62.5 & -61.0 & -60.5 & -61.0 & -62.5 & -65.0 & -68.5 & 73.0 & -78.5 & -85.0 & -92.5 & 101.0 & 10.5 & 121.0 & -132.5 \\
\hline 2 & -122.0 & 10.5 & 100.0 & 90.5 & -82.0 & -74.5 & -68.0 & -62.5 & -58.0 & -54.5 & -52.0 & -50.5 & -50.0 & -50.5 & -52.0 & 54.5 & 58.0 & -62.5 & -68.0 & -74.5 & -82.0 & 90.5 & -100.0 & 110.5 & -122.0 \\
\hline 3 & 112.5 & b1.0 & 90.5 & -81.0 & -72.5 & 65.0 & -58.5 & -53.0 & -48.5 & -45.0 & -42.5 & -41.0 & -40.5 & -41.0 & -42.5 & -45.0 & -48.5 & -53.0 & -58.5 & -65.0 & -72.5 & -81.0 & -90.5 & 101.0 & 12.5 \\
\hline 4 & 104.0 & -92.5 & -82.0 & -72.5 & -64.0 & -56.5 & -50.0 & -44.5 & -40.0 & -36.5 & -34.0 & -32.5 & -32.0 & -32.5 & -34.0 & -36.5 & -40.0 & 44.5 & -50.0 & -56.5 & -64.0 & -72.5 & -82.0 & 92.5 & -104.0 \\
\hline 5 & -96.5 & -85.0 & 74.5 & -65.0 & -56.5 & -49.0 & -42.5 & 37.0 & -32.5 & 29.0 & -26.5 & -25.0 & -24.5 & -25.0 & -26.5 & -29.0 & -32.5 & -37.0 & -42.5 & -49.0 & -56.5 & -65.0 & 74.5 & 85.0 & 96.5 \\
\hline 6 & -90.0 & 78.5 & 68.0 & 58.5 & 0.0 & 2.5 & -36.0 & 0.5 & -26.0 & 2.5 & -20.0 & -18.5 & -18.0 & -18.5 & 20.0 & -22.5 & -26.0 & -30.5 & -36.0 & -42.5 & -50.0 & 58.5 & 68.0 & 78.5 & 90.0 \\
\hline 7 & 84.5 & 3.0 & 2.5 & 3.0 & 4.5 & 37.0 & 30.5 & 5.0 & -20.5 & 7.0 & 4.5 & 13.0 & 2.5 & 13.0 & 14.5 & 17.0 & 20.5 & -25.0 & -30.5 & 37.0 & 44.5 & 53.0 & 52.5 & 73.0 & 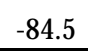 \\
\hline 8 & 80.0 & 8.5 & 8.0 & 8.5 & .0 & 2.5 & 6.0 & 0.5 & 5.0 & .5 & 0.0 & -8.5 & -8.0 & -8.5 & 0.0 & 2.5 & 16.0 & 20.5 & 26.0 & 32.5 & 0.0 & 48.5 & 8.0 & 8.5 & -80.0 \\
\hline 9 & 76.5 & 5.0 & 1.5 & 5.0 & 5.5 & .0 & 2.5 & 7.0 & -12.5 & -9.0 & -6.5 & -5.0 & -4.5 & -5.0 & -6.5 & 9.0 & 2.5 & 7.0 & 22.5 & 29.0 & 6.5 & 15.0 & 4.5 & 5.0 & -76.5 \\
\hline 10 & 4.0 & 2.5 & 0 & 5 & -34.0 & 5 & 0.0 & -14.5 & م017 & -6.5 & -4.0 & -2.5 & 20 & -2.5 & -4.0 & .5 & 0 & 5 & .0 & -26.5 & 1.0 & .5 & 2.0 & 2.5 & -74.0 \\
\hline 11 & 2.5 & L.O & .5 & 0 & .5 & 0 & 3.5 & -13.0 & -8.5 & 50 & 2.5 & -1.0 & -0.5 & -1.0 & -2.5 & -5.0 & 5 & -13.0 & 3.5 & 0 & 2.5 & .0 & .5 & 1.0 & -72.5 \\
\hline 12 & -72.0 & .5 & .0 & -40.5 & 2.0 & 5 & 8.0 & | & -8.0 & -4.5 & -2.0 & -0.5 & 0.0 & -0.5 & -2.0 & -4.5 & 0 & -12.5 & 3.0 & -24.5 & 2.0 & .5 & -50.0 & 0.5 & 72.0 \\
\hline 13 & 2.5 & L.O & .5 & 0 & -32.5 & 0 & 5 & -13.0 & -8.5 & -5.0 & 5 & -1.0 & -0.5 & -1.0 & -2.5 & -5.0 & 5 & 0 & 3.5 & 0 & .5 & .0 & 505 & 1.0 & -72.5 \\
\hline 14 & 74.0 & 2.5 & 2.0 & -42.5 & 4.0 & .5 & 20.0 & 5 & 0.0 & -0.5 & -4.0 & -2.5 & -2.0 & -2.5 & -4 & -0.5 & 0 & -14.5 & 0 & 5 & -34.0 & .5 & 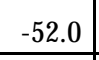 & -62.5 & -74.0 \\
\hline 15 & -76.5 & 5.0 & 5 & -45.0 & -36.5 & 0 & -22.5 & -17.0 & $-12 . J$ & & -6.5 & -5.0 & -4.5 & -5.0 & -6.5 & -9.0 & 5 & -17.0 & .5 & 0 & -36.5 & 0 & -54.5 & 0 & -76.5 \\
\hline 16 & -80.0 & 8.5 & 30 & -48.5 & -40.0 & 5 & -26.0 & -20.5 & -16.0 & & -10.0 & -8.5 & -0.0 & -8.5 & 0 & $-12 . J$ & 0 & -20.5 & .0 & 5 & -40.0 & 18.5 & -58.0 & 3.5 & -80.0 \\
\hline 17 & 84.5 & 3.0 & -62.5 & -53.0 & -44.5 & 0 & -30.5 & -25.0 & -20.5 & -17.0 & 1.5 & 0 & -12.5 & 0 & 5 & $-1 / .0$ & 5 & -25.0 & .5 & 0 & 4.5 & .0 & -62.5 & 3.0 & -84.5 \\
\hline 18 & -90.0 & 8.5 & 30 & 3.5 & 0.0 & 2.5 & 5.0 & -30.5 & .0 & -22.5 & 0.0 & .5 & 8.0 & 3.5 & 20.0 & 2.5 & 26.0 & -30.5 & 36.0 & 42.5 & 0.0 & 58.5 & 8.0 & 78.5 & 90.0 \\
\hline 19 & -96.5 & 5.0 & 4.5 & 55.0 & 6.5 & -49.0 & -42.5 & 7.0 & 32.5 & 0 & 6.5 & -25.0 & 4.5 & 5.0 & 26.5 & 29.0 & 32.5 & 37.0 & -42.5 & -49.0 & 56.5 & 65.0 & 74.5 & 85.0 & -96.5 \\
\hline 20 & 4.0 & 2.5 & 2.0 & 2.5 & 4.0 & -56.5 & 50.0 & 4.5 & 40.0 & 6.5 & 4.0 & 32.5 & 32.0 & 2.5 & 34.0 & 36.5 & 40.0 & -44.5 & -50.0 & 56.5 & 54.0 & 72.5 & 82.0 & 92.5 & 104.0 \\
\hline 21 & -112.5 & 1.0 & 0.5 & 31.0 & 2.5 & -65.0 & 58.5 & 3.0 & -48.5 & 15.0 & 2.5 & -41.0 & 0.5 & 1.0 & 42.5 & 45.0 & -48.5 & -53.0 & -58.5 & -65.0 & 2.5 & 81.0 & 90.5 & 01.0 & 12.5 \\
\hline 22 & -122.0 & 10.5 & 00.0 & 90.5 & -82.0 & -74.5 & -68.0 & -62.5 & -58.0 & -54.5 & 52.0 & -50.5 & -50.0 & -50.5 & 52.0 & -54.5 & -58.0 & -62.5 & -68.0 & -74.5 & -82.0 & 90.5. & -100.0 & -110.5 & -122.0 \\
\hline 23 & -132.5 & -121.0 & -110.5 & -101.0 & -92.5 & -85.0 & -78.5 & -73.0 & -68.5 & -65.0 & -62.5 & -61.0 & -60.5 & -61.0 & -62.5 & -65.0 & -68.5 & -73.0 & -78.5 & -85.0 & -92.5 & -101.0 & -110.5 & -121.0 & -132.5 \\
\hline 24 & -144.0 & -132.5 & -122.0 & -112.5 & -104.0 & -96.5 & -90.0 & -84.5 & -80.0 & -76.5 & -74.0 & -72.5 & -72.0 & -72.5 & -74.0 & -76.5 & -80.0 & -84.5 & -90.0 & -96.5 & -104.0 & -112.5 & -122.0 & -132.5 & -144. \\
\hline
\end{tabular}

Table C-3. Payoff Table of Type 1 for a Groves Mechanism with Single-Peaked Preferences. 


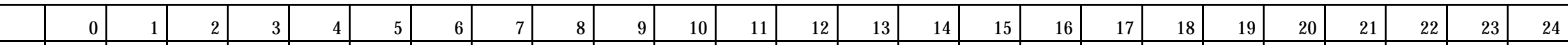
\begin{tabular}{l|r|r|r|r|r|r|r|r|r|r|r|r|r|r|r|r|r|r|r|r|r|r|r|r|r|r|r|r|r|r|r|r|r|}
0 & -289.0 & -272.5 & -257.0 & -242.5 & -229.0 & -216.5 & -205.0 & -194.5 & -185.0 & -176.5 & -169.0 & -162.5 & -157.0 & -152.5 & -149.0 & -146.5 & -145.0 & -144.5 & -145.0 & -146.5 & -149.0 & -152.5 & -157.0 & -162.5 & -169.0 \\
\hline
\end{tabular}

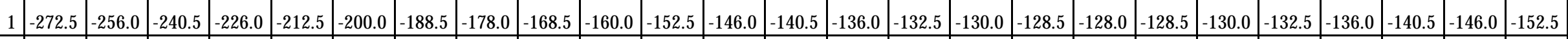
\begin{tabular}{l|l|l|l|l|l|l|l|l|l|l|l|l|l|l|l|l|l|l|l|l|l|l|l|l|l|l|l|l|l|l|l}
2 & -257.0 & -240.5 & -225.0 & -210.5 & -197.0 & -184.5 & -173.0 & -162.5 & -153.0 & -144.5 & -137.0 & -130.5 & -125.0 & -120.5 & -117.0 & -114.5 & -113.0 & -112.5 & -113.0 & -114.5 & -117.0 & -120.5 & -125.0 & -130.5 & -137.0 \\
\hline
\end{tabular} \begin{tabular}{l|l|l|l|l|l|l|l|l|l|l|l|l|l|l|l|l|l|l|l|l|l|l|l|l|l|l|l|l|l|l|l|l|l|l|l|l|}
\hline & -242.5 & -226.0 & -210.5 & -196.0 & -182.5 & -170.0 & -158.5 & -148.0 & -138.5 & -130.0 & -122.5 & -116.0 & -110.5 & -106.0 & -102.5 & -100.0 & -98.5 & -98.0 & -98.5 & -100.0 & -102.5 & -106.0 & -110.5 & -116.0 & -122.5 \\
\hline
\end{tabular} \begin{tabular}{|l|l|l|l|l|l|l|l|l|l|l|l|l|l|l|l|l|l|l|l|l|l|l|l|l|l|l|l|l|l|}
\hline 4 & -229.0 & -212.5 & -197.0 & -182.5 & -169.0 & -156.5 & -145.0 & -134.5 & -125.0 & -116.5 & -109.0 & -102.5 & -97.0 & -92.5 & -89.0 & -86.5 & -85.0 & -84.5 & -85.0 & -86.5 & -89.0 & -92.5 & -97.0 & -102.5 & -109.0 \\
\hline
\end{tabular} \begin{tabular}{l|l|l|l|l|l|l|l|l|l|l|l|l|l|l|l|l|l|l|l|l|l|l|l|l|l|l|l|l|l|l|}
5 & -216.5 & -200.0 & -184.5 & -170.0 & -156.5 & -144.0 & -132.5 & -122.0 & -112.5 & -104.0 & -96.5 & -90.0 & -84.5 & -80.0 & -76.5 & -74.0 & -72.5 & -72.0 & -72.5 & -74.0 & -76.5 & -80.0 & -84.5 & -90.0 & -96.5 \\
\hline
\end{tabular}

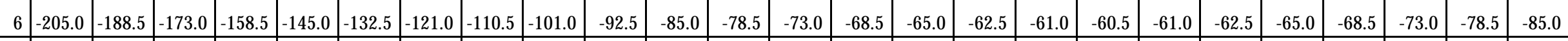

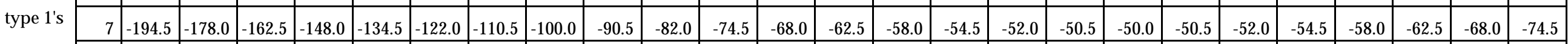

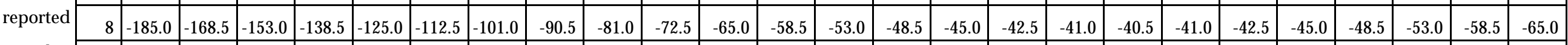
peak

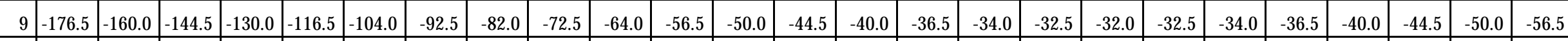

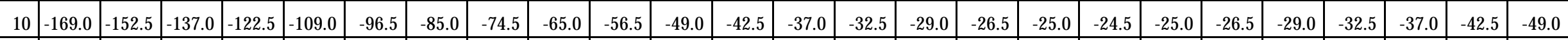

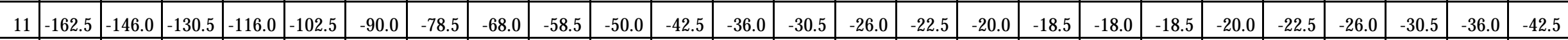

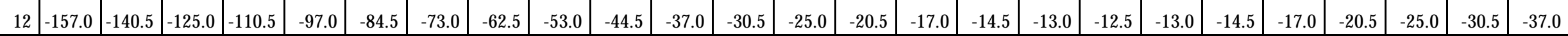

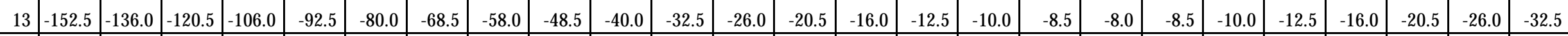

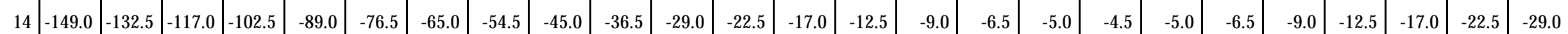

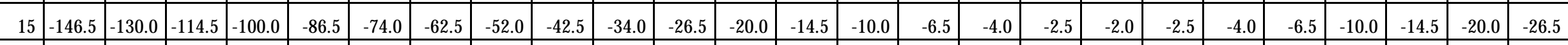

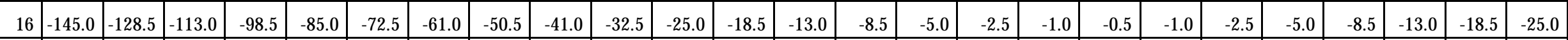

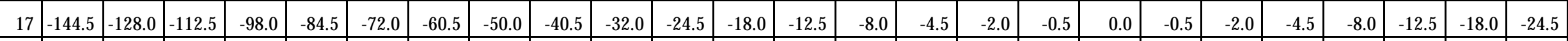

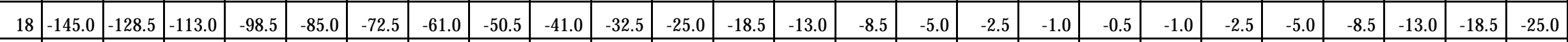

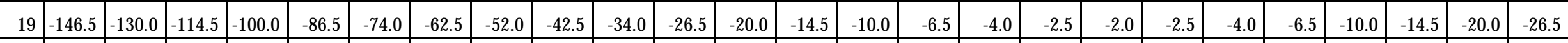

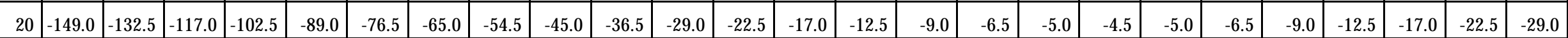
\begin{tabular}{l|l|l|l|l|l|l|l|l|l|l|l|l|l|l|l|l|l|l|l|l|l|l|l|l|l|l|l|l|l|l|l|}
21 & -152.5 & -136.0 & -120.5 & -106.0 & -92.5 & -80.0 & -68.5 & -58.0 & -48.5 & -40.0 & -32.5 & -26.0 & -20.5 & -16.0 & -12.5 & -10.0 & -8.5 & -8.0 & -8.5 & -10.0 & -12.5 & -16.0 & -20.5 & -26.0 & -32.5 \\
\hline
\end{tabular}

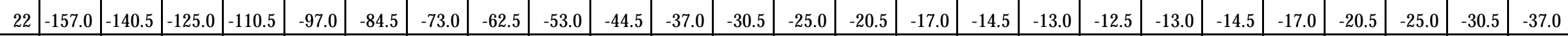

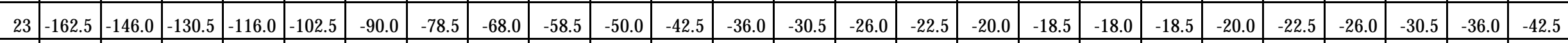

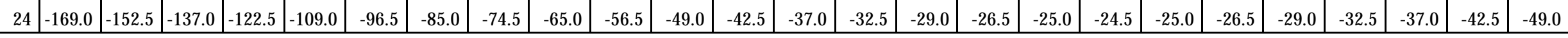

Table C-4. Payoff Table of Type 2 for a Groves Mechanism with Single-Peaked Preferences. 
The number which you choose (Type 1)

The number which the other person chooses (Type 2)

\begin{tabular}{|c|c|c|c|c|c|c|c|c|c|c|c|c|c|c|c|c|c|c|c|c|c|c|c|c|c|}
\hline & & 2 & 3 & 4 & 5 & 0 & 1 & & & & & 12 & 13 & + & 15 & 16 & 17 & 18 & 19 & 20 & 21 & 22 & 23 & $2 \pi$ & \\
\hline . & 4 & 4 & 34 & 44 & 4 & 44 & 4 & 4 & 4 & 94 & & & & 34 & & & & & & & & & & & \\
\hline 2 & & & & & & & & & & & & & & & & & & & & 4 & 4 & & & & \\
\hline 3 & & & & & & & & & & & & & & & & & & & & & & & & & \\
\hline 4 & & & & & & & & & & & & & & & & & 4 & 4 & 4 & 4 & 4 & 34 & 24 & & \\
\hline 5 & & & & & 4 & 4 & 4 & 4 & 4 & 94 & 4 & 4 & 4 & 4 & 4 & 44 & 94 & 94 & 94 & 94 & 4 & 294 & 10 & 10 & \\
\hline 6 & 30 & 30 & 30 & 30 & 80 & 80 & 30 & 30 & 30 & 280 & 80 & 280 & 280 & 280 & 280 & 280 & 280 & 280 & 80 & 80 & 80 & 10 & 10 & 10 & 1 \\
\hline 7 & 56 & 56 & 56 & 56 & 66 & 66 & 66 & 56 & 66 & 266 & 266 & 266 & 266 & 266 & 266 & 56 & 66 & 266 & 66 & 66 & 10 & 10 & 10 & 10 & 1 \\
\hline 8 & 2 & 2 & 2 & 2 & 2 & 2 & 2 & 2 & 2 & 2 & 252 & 252 & 252 & 252 & 252 & 2 & 52 & 52 & 52 & 10 & 10 & 10 & 10 & 10 & 1 \\
\hline 9 & 38 & 38 & 38 & 38 & 38 & 38 & 38 & 238 & 238 & 238 & 238 & 238 & 238 & 238 & 238 & 238 & 238 & 238 & 10 & 10 & 10 & 10 & 10 & 10 & 10 \\
\hline 0 & 24 & 24 & 24 & 24 & 24 & 24 & 224 & 224 & 224 & 224 & 224 & 224 & 224 & 224 & 224 & 224 & 224 & 210 & 210 & 210 & 210 & 210 & 10 & 10 & \\
\hline I. & $\mathrm{LO}$ & 0 & 10 & 10 & 10 & 10 & 10 & 210 & 210 & 210 & 210 & 210 & 210 & 210 & 210 & 210 & 10 & 10 & 10 & 10 & 10 & 10 & 10 & 210 & \\
\hline 12 & 36 & 66 & 66 & 96 & 96 & 96 & 6 & 6 & 96 & 96 & 196 & 196 & 196 & 196 & 196 & 210 & 210 & 210 & 210 & 210 & 210 & 210 & 10 & 210 & \\
\hline 13 & 32 & 32 & 32 & 82 & 82 & 82 & 182 & 182 & 182 & 182 & 182 & 182 & 182 & \begin{tabular}{|l|}
182 \\
\end{tabular} & 10 & 210 & | 210 & 210 & 210 & 210 & 210 & 210 & 210 & 210 & 1 \\
\hline 14 & 58 & 58 & 68 & 68 & 68 & 168 & 168 & 168 & 168 & 68 & 168 & 16 & 168 & 210 & 210 & $\overline{10}$ & $\overline{17}$ & 70 & 70 & 210 & 210 & ח10 & 210 & 210 & \\
\hline 15 & 84 & & & 54 & 54 & 154 & 754 & 154 & 154 & 154 & 154 & 154 & 210 & 210 & 210 & 210 & 210 & 210 & 210 & 210 & 210 & & 210 & 270 & \\
\hline 16 & 40 & & & 40 & 140 & 140 & 140 & 140 & 140 & 140 & 140 & 210 & 210 & 210 & 210 & 210 & 7 & 210 & 210 & 210 & 210 & 210 & 270 & 210 & \\
\hline 17 & 26 & & & 26 & 26 & 126 & 126 & 126 & 126 & 126 & 210 & 210 & 210 & 210 & 210 & 210 & 210 & 210 & & 210 & & & & & \\
\hline 18 & 2 & 12 & 112 & 112 & 112 & 172 & 112 & 112 & 112 & 21 & 21 & 21 & 21 & 2 & 2 & 2 & 210 & 210 & 210 & 210 & 210 & ח12 & 210 & 210 & \\
\hline & 98 & & & & & & & & م20 & 210 & 2 & 2 & 2 & 2 & & & & & & & & & & & \\
\hline & $\overline{01}$ & & 84 & 84 & 84 & 84 & 84 & 210 & 210 & 210 & 210 & 210 & 210 & 210 & 2 & 210 & 210 & 210 & 210 & 210 & 270 & חיר & 210 & 210 & \\
\hline & & & 70 & 70 & 70 & 70 & 210 & 210 & 210 & 210 & 210 & 210 & 210 & 210 & 210 & 210 & 210 & 210 & 210 & 210 & 210 & $2 \Delta$ & $2+0$ & $- \pm v$ & \\
\hline & 0 & & 56 & 56 & 56 & 210 & 210 & 210 & 210 & 210 & 210 & 210 & 210 & 210 & 210 & 210 & 210 & 210 & 210 & 210 & 210 & $\angle 10$ & 210 & $=10$ & 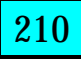 \\
\hline & 42 & 42 & 42 & 42 & 10 & $\angle 10$ & 210 & 210 & 210 & 210 & 210 & 210 & 210 & 210 & 210 & 210 & 210 & 210 & 210 & 210 & 210 & $\angle \perp 0$ & $\angle \perp 0$ & $\angle D$ & . \\
\hline 2 & 28 & 28 & 20 & 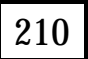 & $x^{2}$ & $2+4$ & $2 \pm 0$ & 21 & $\angle \pm$ & 21 & 21 & 210 & 2. & $2 \pm$ & $2 \perp$ & 210 & & & & & & & & $6 \perp 0$ & 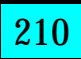 \\
\hline 25 & 14 & 14 & 0 & 10 & 10 & 10 & 10 & 10 & 10 & 10 & 10 & 10 & 210 & 210 & 10 & 210 & 210 & 10 & 10 & 10 & 10 & 10 & 10 & 210 & \\
\hline
\end{tabular}

Table 1. Dominant Strategy Equilibria and N ash Equilibria for Payoff Table of Type 1 in Treatment P. 
The number which you choose (Type 2)

The number which the other person chooses

(Type 1)

\begin{tabular}{|c|c|c|c|c|c|c|c|c|c|c|c|c|c|c|c|c|c|c|c|c|c|c|c|c|c|}
\hline & 1 & 2 & 3 & 4 & 5 & 6 & 7 & 8 & 9 & 10 & 11 & 12 & 13 & 14 & 15 & 16 & 17 & 18 & 19 & 20 & 21 & 22 & 23 & 24 & 25 \\
\hline 1 & 32 & 2 & 2 & 2 & 2 & 2 & 2 & 32 & 32 & 32 & 32 & 182 & 82 & 82 & 82 & 82 & 182 & 182 & 182 & 182 & 182 & 182 & 182 & 182 & 182 \\
\hline 2 & 82 & 32 & 32 & 22 & 22 & 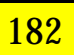 & 02 & 02 & 82 & 82 & 82 & 182 & 82 & 182 & 82 & 182 & 182 & 182 & 182 & 182 & 182 & 182 & 182 & 182 & 182 \\
\hline 3 & 82 & 82 & 182 & 182 & 182 & 182 & 182 & 32 & 32 & 182 & 182 & 182 & 182 & 182 & 182 & 182 & 182 & 182 & 182 & 182 & 182 & 182 & 182 & 182 & \\
\hline 4 & 82 & 182 & 182 & 182 & 182 & 182 & 182 & 182 & 182 & 182 & 182 & 182 & 182 & 182 & 182 & 182 & 182 & 182 & 182 & 182 & 182 & 182 & 182 & 28 & 28 \\
\hline 5 & 82 & 182 & 182 & 182 & 182 & 182 & 182 & 182 & 182 & 182 & 182 & 182 & 182 & 182 & 182 & 182 & 182 & 182 & 182 & 182 & 182 & 182 & 42 & 42 & 42 \\
\hline 6 & 82 & 82 & 182 & 182 & 182 & 182 & 182 & 182 & 182 & 182 & 182 & 182 & 182 & 182 & 182 & 182 & 182 & 182 & 182 & 182 & 182 & 56 & 56 & 56 & 56 \\
\hline 7 & 82 & 82 & 182 & 182 & 182 & 182 & 182 & 32 & 182 & 182 & 182 & 182 & 182 & 182 & 182 & 182 & 182 & 182 & 182 & 182 & 70 & 70 & 70 & 70 & 70 \\
\hline 8 & 182 & 182 & 182 & 182 & 182 & 182 & 182 & 182 & 182 & 182 & 182 & 182 & 182 & 182 & 182 & 182 & 182 & 182 & 182 & 84 & 84 & 84 & 84 & 84 & 84 \\
\hline 9 & 182 & 182 & 182 & 182 & 182 & 182 & 182 & 182 & 182 & 182 & 182 & 182 & 182 & 182 & 182 & 182 & 182 & 182 & 98 & 98 & 98 & 98 & 98 & 98 & 98 \\
\hline 10 & 182 & 182 & 182 & 182 & 182 & 182 & 182 & 182 & 182 & 182 & 182 & 182 & 182 & 182 & 182 & 182 & 182 & 112 & 112 & 112 & 112 & 112 & 112 & 112 & 112 \\
\hline 11 & 182 & 182 & 182 & 182 & 182 & 182 & 182 & 182 & 182 & 182 & 182 & 182 & 182 & 182 & 182 & 182 & 126 & 126 & 126 & 126 & 126 & 126 & 126 & 26 & 126 \\
\hline 12 & 182 & 182 & 182 & 182 & 182 & 182 & 182 & 182 & 182 & 182 & 182 & 182 & 182 & 182 & 182 & 140 & 140 & 140 & 140 & 140 & 140 & 140 & 140 & 140 & 40 \\
\hline 13 & 182 & 182 & 182 & 182 & 182 & 182 & 182 & 182 & 182 & 182 & 182 & 182 & 182 & 182 & 154 & 154 & 154 & 154 & 154 & 154 & 154 & 154 & 154 & 154 & 154 \\
\hline 14 & 182 & 182 & 182 & 182 & 182 & 182 & 182 & 182 & 182 & 182 & 182 & 182 & 182 & 168 & 168 & 168 & 168 & 168 & 168 & 168 & 168 & 168 & 168 & 168 & 168 \\
\hline 15 & 182 & 182 & 182 & 182 & 182 & 182 & 182 & 82 & 82 & 182 & 182 & 182 & 182 & 182 & 182 & 182 & 182 & 182 & 182 & 182 & 182 & 182 & 182 & 182 & 182 \\
\hline 16 & 182 & 182 & 182 & 182 & 182 & 182 & 182 & 82 & 182 & 182 & 182 & 196 & 196 & 196 & 196 & 196 & 196 & 196 & 196 & 196 & 196 & 196 & 196 & 196 & 196 \\
\hline 17 & 182 & 182 & 182 & 182 & 182 & 182 & 182 & 182 & 182 & 182 & 210 & 210 & 210 & 210 & 210 & 210 & 210 & 210 & 210 & 210 & 210 & 210 & 210 & 210 & 210 \\
\hline 18 & 182 & 182 & 182 & 182 & 182 & 182 & 182 & 182 & 182 & 224 & 224 & 224 & 224 & 224 & 224 & 224 & 224 & 224 & 224 & 224 & 224 & 224 & 224 & 224 & 224 \\
\hline 19 & 182 & 182 & 182 & 182 & 182 & 182 & 182 & 182 & 238 & 238 & 238 & 238 & 238 & 238 & 238 & 238 & 238 & 238 & 238 & 238 & 238 & 238 & 238 & 238 & 238 \\
\hline 20 & 182 & 182 & 182 & 182 & 182 & 182 & 182 & 252 & 252 & 252 & 252 & 252 & 252 & 252 & 252 & 252 & 252 & 252 & 252 & 252 & 252 & 252 & 252 & 252 & 252 \\
\hline 21 & 182 & 182 & 182 & 182 & 182 & 182 & 266 & 266 & 266 & 266 & 266 & 266 & 266 & 266 & 266 & 266 & 266 & 266 & 266 & 266 & 266 & 266 & 266 & 266 & 266 \\
\hline 22 & 182 & 182 & 182 & 182 & 182 & 280 & 280 & 280 & 280 & 280 & 280 & 280 & 280 & 280 & 280 & 280 & 280 & 280 & 280 & 280 & 280 & 280 & 280 & 280 & 280 \\
\hline 23 & 182 & 182 & 182 & 182 & 294 & 294 & 294 & 294 & 294 & 294 & 294 & 294 & 294 & 294 & 294 & 294 & 294 & 294 & 294 & 294 & 294 & 294 & 294 & 294 & 294 \\
\hline 24 & 168 & 168 & 168 & 294 & 294 & 294 & 294 & 294 & 294 & 294 & 294 & 294 & 294 & 294 & 294 & 294 & 294 & 294 & 294 & 294 & 294 & 294 & 294 & 294 & 294 \\
\hline 25 & 154 & 154 & 294 & 294 & 294 & 294 & 294 & 294 & 294 & 294 & 294 & 294 & 294 & 294 & 294 & 294 & 294 & 294 & 294 & 294 & 294 & 294 & 294 & 294 & 294 \\
\hline
\end{tabular}

Table 2. Dominant Strategy Equilibria and Nash Equilibria for Payoff Table of Type 2 in Treatment P. 
The number which you choose

The number which the other person chooses

\begin{tabular}{|c|c|c|c|c|c|c|c|c|c|c|c|c|c|c|c|c|c|c|c|c|c|c|c|c|c|}
\hline & & & & & & & & & \\
\hline & & & & & & & & & & & & & & & & & & & & & & & & & 25 \\
\hline & 116 & 24 & 131 & 138 & 144 & 50 & & & 61 & 164 & 166 & 67 & 67 & 57 & 66 & 164 & 161 & 158 & 54 & 50 & 44 & 138 & 131 & 124 & 116 \\
\hline 2 & 24 & 32 & 40 & 46 & 152 & 158 & 52 & 6 & 170 & 172 & 174 & 175 & 175 & 75 & 174 & 172 & 170 & 166 & 162 & 158 & 152 & 146 & 140 & 132 & 124 \\
\hline 3 & 1 & 10 & 17 & 154 & 160 & 65 & .10 & 74 & 177 & 180 & 181 & 182 & 183 & 182 & 181 & 180 & 177 & 174 & 170 & 165 & 160 & 154 & 147 & 140 & 131 \\
\hline 4 & 138 & 6 & 4 & 161 & 167 & 172 & 177 & 181 & 84 & 186 & 188 & 189 & 190 & 39 & 188 & 186 & 184 & 181 & 177 & 172 & 167 & 161 & 154 & 146 & 138 \\
\hline 5 & 44 & 2 & 60 & 67 & 73 & 78 & 183 & 7 & 190 & 192 & 194 & 195 & 96 & 95 & 194 & \begin{tabular}{|l|}
192 \\
\end{tabular} & 190 & 187 & 183 & 178 & 173 & 167 & 160 & 152 & $14 k$ \\
\hline 6 & 50 & 88 & 165 & 172 & 178 & 84 & 188 & 92 & 195 & 198 & 200 & 201 & 201 & 201 & 200 & 198 & 195 & 192 & 188 & 184 & \begin{tabular}{|l|}
178 \\
\end{tabular} & 172 & 165 & 158 & 150 \\
\hline 7 & 154 & 52 & 170 & $\mid 177$ & 183 & 188 & 193 & 197 & 200 & 202 & 204 & 205 & 206 & 205 & 204 & 202 & 200 & 197 & 193 & 188 & 183 & 177 & 170 & 162 & 154 \\
\hline 8 & 58 & 6 & 174 & 81 & 187 & 92 & 197 & 1 & 204 & 206 & 208 & 209 & 210 & 209 & 208 & 206 & 204 & 201 & \begin{tabular}{|l|}
197 \\
\end{tabular} & 192 & 187 & 181 & 174 & 166 & 158 \\
\hline 9 & 1 & 0 & 77 & \begin{tabular}{|l|}
184 \\
\end{tabular} & 30 & 195 & 200 & 04 & 207 & 210 & 211 & 212 & 213 & 212 & 211 & 210 & 207 & 204 & 200 & 195 & \begin{tabular}{|l|}
190 \\
\end{tabular} & \begin{tabular}{|l|l}
184 \\
\end{tabular} & 177 & 170 & 16 \\
\hline 10 & 54 & 2 & 180 & 186 & \begin{tabular}{|l|}
192 \\
\end{tabular} & 198 & 202 & 206 & 210 & 212 & 214 & 215 & 215 & 215 & 214 & 212 & 210 & 206 & 202 & 198 & 192 & 186 & 180 & 172 & 164 \\
\hline 11 & 66 & 74 & 181 & 188 & 194 & 200 & 204 & 208 & 211 & 214 & 216 & 217 & 217 & 217 & 216 & 214 & 211 & 208 & 204 & 200 & 194 & 188 & 181 & 174 & 166 \\
\hline 12 & 77 & 5 & 182 & 189 & 195 & 01 & 205 & 209 & 212 & \begin{tabular}{|l|}
215 \\
\end{tabular} & 217 & 218 & 218 & 218 & 217 & 215 & 212 & 209 & 205 & 201 & \begin{tabular}{|l|}
195 \\
\end{tabular} & 189 & 182 & 175 & 167 \\
\hline 13 & 57 & 75 & 183 & 190 & 196 & 201 & 206 & 210 & 213 & 215 & 217 & 218 & 219 & 218 & 217 & 215 & 213 & 210 & 206 & 201 & 196 & 190 & 183 & 175 & 167 \\
\hline 14 & 67 & 75 & \begin{tabular}{|l}
182 \\
\end{tabular} & 189 & \begin{tabular}{|l|}
195 \\
\end{tabular} & 201 & 205 & 209 & 212 & 215 & 217 & 218 & 218 & 218 & 217 & 215 & 212 & 209 & 205 & 201 & \begin{tabular}{|l|}
195 \\
\end{tabular} & \begin{tabular}{|l}
189 \\
\end{tabular} & \begin{tabular}{|l|}
182 \\
\end{tabular} & 175 & 167 \\
\hline 15 & 66 & 4 & 181 & \begin{tabular}{|l|}
188 \\
\end{tabular} & 194 & 200 & 204 & 208 & 211 & 214 & 216 & 217 & 217 & 217 & 216 & 214 & 211 & 208 & 204 & 200 & 194 & 188 & 181 & 174 & 166 \\
\hline 16 & 54 & 2 & \begin{tabular}{|l|}
180 \\
\end{tabular} & 186 & \begin{tabular}{|l|}
192 \\
\end{tabular} & \begin{tabular}{|l|}
198 \\
\end{tabular} & 202 & 206 & 210 & 212 & 214 & 215 & \begin{tabular}{|l|}
215 \\
\end{tabular} & 215 & 214 & 212 & 210 & 206 & 202 & 198 & \begin{tabular}{|l|}
192 \\
\end{tabular} & 186 & \begin{tabular}{|l|}
180 \\
\end{tabular} & 172 & 164 \\
\hline 17 & 161 & 170 & \begin{tabular}{|l|l}
177 \\
\end{tabular} & \begin{tabular}{|l|}
184 \\
\end{tabular} & 190 & \begin{tabular}{|l|}
195 \\
\end{tabular} & 200 & 204 & 207 & 210 & 211 & 212 & 213 & 212 & 211 & 210 & 207 & 204 & 200 & 195 & \begin{tabular}{|l|}
190 \\
\end{tabular} & \begin{tabular}{|l|l}
184 \\
\end{tabular} & \begin{tabular}{|l|l|}
177 \\
\end{tabular} & 170 & 161 \\
\hline 18 & 158 & 66 & 174 & 181 & 187 & \begin{tabular}{|l|}
192 \\
\end{tabular} & 197 & 201 & 204 & 206 & 208 & 209 & 210 & 209 & 208 & 206 & 204 & 201 & 197 & 192 & 187 & 181 & 174 & 166 & 158 \\
\hline 19 & 54 & 52 & \begin{tabular}{|l|}
170 \\
\end{tabular} & 177 & 183 & \begin{tabular}{|l|}
188 \\
\end{tabular} & \begin{tabular}{|l|}
193 \\
\end{tabular} & 197 & 200 & 202 & 204 & 205 & 206 & 205 & 204 & 202 & 200 & 197 & \begin{tabular}{|l|}
193 \\
\end{tabular} & 188 & 183 & 177 & \begin{tabular}{|l|}
170 \\
\end{tabular} & 162 & 154 \\
\hline 20 & 150 & 158 & 165 & 172 & \begin{tabular}{|l|}
178 \\
\end{tabular} & 184 & 188 & 192 & 195 & \begin{tabular}{|l|}
198 \\
\end{tabular} & 200 & 201 & 201 & 201 & 200 & \begin{tabular}{|l|}
198 \\
\end{tabular} & 195 & 192 & 188 & 184 & \begin{tabular}{|l}
178 \\
\end{tabular} & \begin{tabular}{|l}
172 \\
\end{tabular} & 165 & 158 & 150 \\
\hline 21 & 144 & 152 & \begin{tabular}{|l|}
160 \\
\end{tabular} & 167 & 173 & \begin{tabular}{|l}
178 \\
\end{tabular} & 183 & 187 & \begin{tabular}{|l|}
190 \\
\end{tabular} & 192 & 194 & 195 & 196 & 195 & \begin{tabular}{|l|}
194 \\
\end{tabular} & 192 & 190 & 187 & 183 & 178 & \begin{tabular}{|l|}
173 \\
\end{tabular} & 167 & \begin{tabular}{|l|}
160 \\
\end{tabular} & 152 & 144 \\
\hline 22 & 138 & 146 & \begin{tabular}{|l|l}
154 \\
\end{tabular} & \begin{tabular}{|l|}
161 \\
\end{tabular} & \begin{tabular}{|l|}
167 \\
\end{tabular} & \begin{tabular}{|l}
172 \\
\end{tabular} & 177 & 181 & 184 & 186 & 188 & \begin{tabular}{|l|}
189 \\
\end{tabular} & \begin{tabular}{|l|}
190 \\
\end{tabular} & 189 & \begin{tabular}{|l|}
188 \\
\end{tabular} & 186 & 184 & 181 & 177 & 172 & \begin{tabular}{|l|}
167 \\
\end{tabular} & \begin{tabular}{|l|}
161 \\
\end{tabular} & 154 & 146 & 138 \\
\hline 23 & 131 & 140 & \begin{tabular}{|l|}
147 \\
\end{tabular} & 154 & 160 & 165 & 170 & 174 & 177 & 180 & 181 & 182 & 183 & 182 & \begin{tabular}{|l|}
181 \\
\end{tabular} & 180 & 177 & 174 & 170 & 165 & 160 & 154 & \begin{tabular}{|l|}
147 \\
\end{tabular} & 140 & 131 \\
\hline 24 & 124 & 132 & 140 & 146 & 152 & 158 & 162 & 166 & 170 & 172 & 174 & 175 & 175 & 175 & 174 & 172 & 170 & 166 & 162 & 158 & 152 & 146 & 140 & 132 & 124 \\
\hline 25 & 116 & 124 & 131 & 138 & 144 & 150 & 154 & 158 & 161 & \begin{tabular}{|l|l|} 
\\
\end{tabular} & 166 & 167 & \begin{tabular}{|l|}
167 \\
\end{tabular} & 167 & 166 & \begin{tabular}{|l|}
164 \\
\end{tabular} & 161 & 158 & 154 & 150 & 144 & 138 & \begin{tabular}{|l|}
131 \\
\end{tabular} & 124 & 116 \\
\hline
\end{tabular}

Table 3. Payoff Table of Type 1 distributed in Treatment S. 
The number which you choose

The number \begin{tabular}{|l||l|l|l|l|l|l|l|l|l|l|l|l|l|l|l|l|l|l|l|l|l|l|l|l|l|}
\hline & 1 & 2 & 3 & 4 & 5 & 6 & 7 & 8 & 9 & 10 & 11 & 12 & 13 & 14 & 15 & 16 & 17 & 18 & 19 & 20 & 21 & 22 & 23 & 24 & 25 \\
\hline
\end{tabular} \begin{tabular}{|l|l|l|l|l|l|l|l|l|l|l|l|l|l|l|l|l|l|l|l|l|l|l|l|l|l|}
\hline 1 & 12 & 24 & 35 & 45 & 55 & 64 & 72 & 80 & 86 & 92 & 98 & 102 & 106 & 110 & 112 & 114 & 115 & 115 & 115 & 114 & 112 & 110 & 106 & 102 & 98 \\
\hline
\end{tabular} \begin{tabular}{|l|l|l|l|l|l|l|l|l|l|l|l|l|l|l|l|l|l|l|l|l|l|l|l|l|l|}
\hline 2 & 24 & 36 & 47 & 57 & 67 & 76 & 84 & 91 & 98 & 104 & 110 & 114 & 118 & 121 & 124 & 126 & 127 & 127 & 127 & 126 & 124 & 121 & 118 & 114 & 110 \\
\hline
\end{tabular}

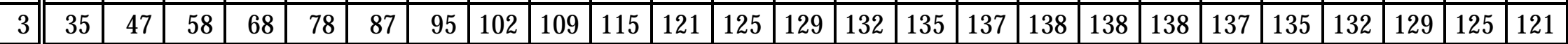

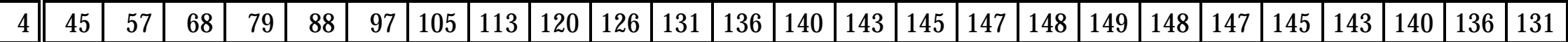

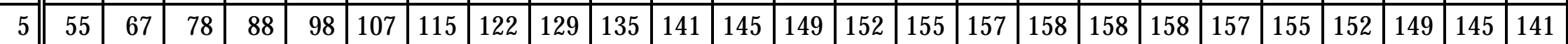

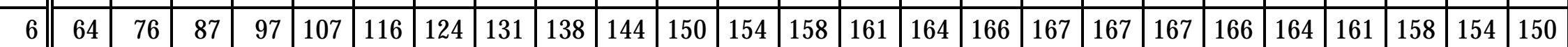

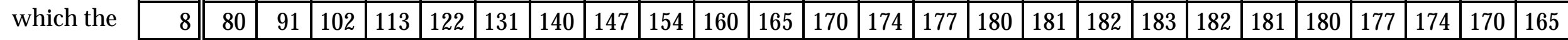

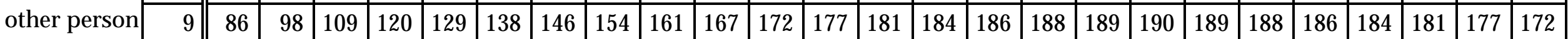

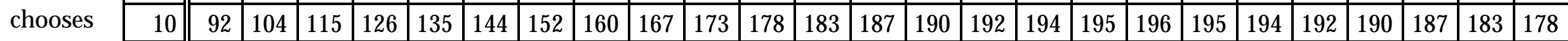

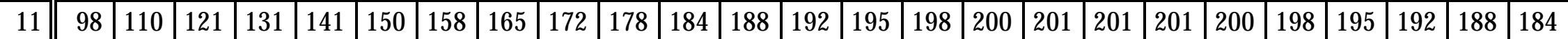

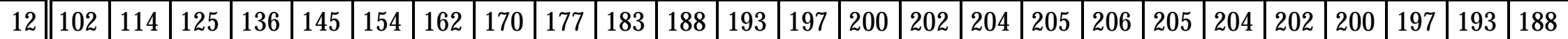
\begin{tabular}{l|l|l|l|l|l|l|l|l|l|l|l|l|l|l|l|l|l|l|l|l|l|l|l|l|l|}
13 & 106 & 118 & 129 & 140 & 149 & 158 & 166 & 174 & 181 & 187 & 192 & 197 & 201 & 204 & 206 & 208 & 209 & 210 & 209 & 208 & 206 & 204 & 201 & 197 & 192 \\
\hline
\end{tabular} \begin{tabular}{l|l|l|l|l|l|l|l|l|l|l|l|l|l|l|l|l|l|l|l|l|l|l|l|l|l|}
14 & 110 & 121 & 132 & 143 & 152 & 161 & 170 & 177 & 184 & 190 & 195 & 200 & 204 & 207 & 210 & 211 & 212 & 213 & 212 & 211 & 210 & 207 & 204 & 200 & 195 \\
\hline
\end{tabular}

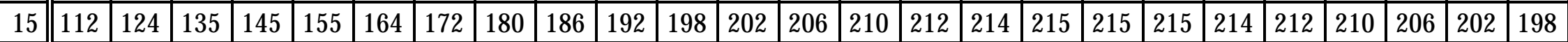

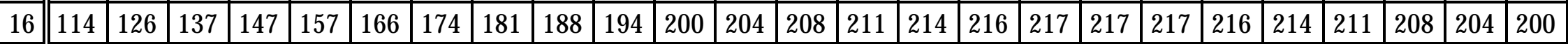

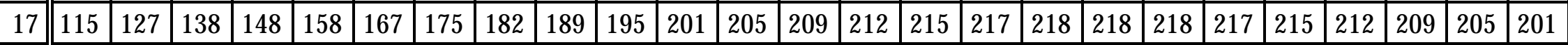

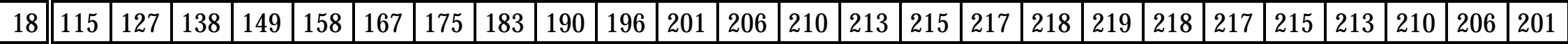

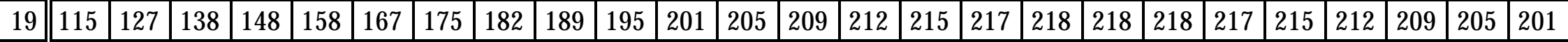
\begin{tabular}{|l|l|l|l|l|l|l|l|l|l|l|l|l|l|l|l|l|l|l|l|l|l|l|l|l|l|}
20 & 114 & 126 & 137 & 147 & 157 & 166 & 174 & 181 & 188 & 194 & 200 & 204 & 208 & 211 & 214 & 216 & 217 & 217 & 217 & 216 & 214 & 211 & 208 & 204 & 200 \\
\hline
\end{tabular} \begin{tabular}{l|lllllllllll|l|l|l|l|l|l|l|l|l|l|l|l|l|l|}
21 & 112 & 124 & 135 & 145 & 155 & 164 & 172 & 180 & 186 & 192 & 198 & 202 & 206 & 210 & 212 & 214 & 215 & 215 & 215 & 214 & 212 & 210 & 206 & 202 & 198 \\
\hline
\end{tabular} \begin{tabular}{|l|l|l|l|l|l|l|l|l|l|l|l|l|l|l|l|l|l|l|l|l|l|l|l|l|l|}
22 & 110 & 121 & 132 & 143 & 152 & 161 & 170 & 177 & 184 & 190 & 195 & 200 & 204 & 207 & 210 & 211 & 212 & 213 & 212 & 211 & 210 & 207 & 204 & 200 & 195 \\
\hline
\end{tabular}

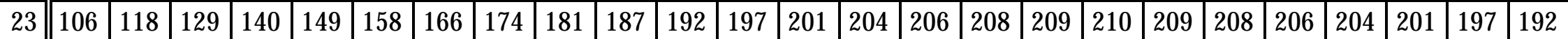
\begin{tabular}{|l|l|l|l|l|l|l|l|l|l|l|l|l|l|l|l|l|l|l|l|l|l|l|l|l|l|}
24 & 102 & 114 & 125 & 136 & 145 & 154 & 162 & 170 & 177 & 183 & 188 & 193 & 197 & 200 & 202 & 204 & 205 & 206 & 205 & 204 & 202 & 200 & 197 & 193 & 188 \\
\hline
\end{tabular} \begin{tabular}{|l|l|l|l|l|l|l|l|l|l|l|l|l|l|l|l|l|l|l|l|l|l|l|l|l|l|}
\hline 25 & 98 & 110 & 121 & 131 & 141 & 150 & 158 & 165 & 172 & 178 & 184 & 188 & 192 & 195 & 198 & 200 & 201 & 201 & 201 & 200 & 198 & 195 & 192 & 188 & 184 \\
\hline
\end{tabular}

Table 4. Payoff Table of Type 2 distributed in Treatment S. 


\begin{tabular}{|c|c|c|}
\hline & $\begin{array}{c}\text { (1) } \\
\begin{array}{c}\text { Individuals play dominant } \\
\text { strategies }\end{array} \\
\end{array}$ & $\begin{array}{l}(2) \\
\text { Pairs play dominant } \\
\text { strategy equilibrium }\end{array}$ \\
\hline $\begin{array}{l}\text { Dummy variable=1 for } \\
\text { Treatment } S\end{array}$ & $\begin{array}{l}0.720^{* *} \\
(0.346)\end{array}$ & $\begin{array}{l}0.887^{* *} \\
(0.143)\end{array}$ \\
\hline $\begin{array}{l}\text { Dummy variable }=1 \text { for } \\
\text { sessions at Purdue }\end{array}$ & & $\begin{array}{c}0.170 \\
(0.142)\end{array}$ \\
\hline Intercept & $\begin{array}{l}1.236^{* *} \\
(0.266)\end{array}$ & $\begin{array}{l}-0.095 \\
(.0122)\end{array}$ \\
\hline $\begin{array}{l}\rho=\sigma_{u}^{2} /\left(\sigma_{v}^{2}+\sigma_{u}^{2}\right) \\
\text { (random effects significance) }\end{array}$ & $\begin{array}{l}0.627^{* *} \\
(0.069)\end{array}$ & \\
\hline Observations & 720 & 360 \\
\hline Log-likelihood & -247.2 & -211.3 \\
\hline Restricted log-likelihood & -344.5 & -231.8 \\
\hline
\end{tabular}

Notes: Standard errors shown in parentheses. ${ }^{* *}$ denotes significantly different from zero at five-percent. Model in column (1) is estimated with a random subjects effect error term $u_{i}+v_{i t}$

Table 5. Probit Models of Individual and Pair Dominant Strategy Play 